\title{
Regional Cellular Environment Shapes Phenotypic Variations of Hippocampal and Neocortical Chandelier Cells
}

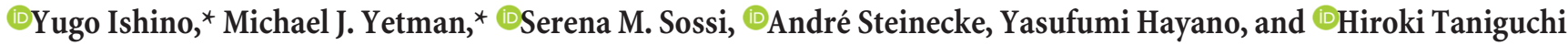 \\ Development and Function of Inhibitory Neural Circuits, Max Planck Florida Institute for Neuroscience, Jupiter, Florida 33458
}

Different cortical regions processing distinct information, such as the hippocampus and the neocortex, share common cellular components and circuit motifs but form unique networks by modifying these cardinal units. Cortical circuits include diverse types of GABAergic interneurons (INs) that shape activity of excitatory principal neurons (PNs). Canonical IN types conserved across distinct cortical regions have been defined by their morphological, electrophysiological, and neurochemical properties. However, it remains largely unknown whether canonical IN types undergo specific modifications in distinct cortical regions and display "regional variants." It is also poorly understood whether such phenotypic variations are shaped by early specification or regional cellular environment. The chandelier cell $(\mathrm{ChC})$ is a highly stereotyped IN type that innervates axon initial segments of PNs and thus serves as a good model with which to address this issue. Here, we show that Cadherin-6 (Cdh6), a homophilic cell adhesion molecule, is a reliable marker of ChCs and Cdh6-CreER mice (both sexes) provide genetic access to hippocampal ChCs (h-ChCs). We demonstrate that, compared with neocortical ChCs (nc-ChCs), h-ChCs cover twice as much area and innervate twice as many PNs. Interestingly, a subclass of h-ChCs exhibits calretinin (CR) expression, which is not found in nc-ChCs. Furthermore, we find that h-ChCs appear to be born earlier than nc-ChCs. Surprisingly, despite the difference in temporal origins, ChCs display host-region-dependent axonal/synaptic organization and CR expression when transplanted heterotopically. These results suggest that local cellular environment plays a critical role in shaping terminal phenotypes of regional IN variants in the hippocampus and the neocortex.

Key words: cell type; chandelier cell; cortical interneuron; hippocampus; neocortex

Significance Statement

Canonical interneuron (IN) types conserved across distinct cortical regions such as the hippocampus and the neocortex are defined by morphology, physiology, and gene expression. However, it remains unknown whether they display phenotypic variations in different cortical regions. In addition, it is unclear whether terminal phenotypes of regional IN variants belonging to a canonical IN type are determined intrinsically or extrinsically. Our results provide evidence of striking differences in axonal/ synaptic organization and calretinin expression between hippocampal chandelier cells (ChCs) and neocortical ChCs. They also reveal that local cellular environment in distinct cortical regions regulates these terminal phenotypes. Therefore, our study suggests that local cortical environment shapes the phenotypes of regional IN variants, which may be required for unique circuit operations in distinct cortical regions.

\section{Introduction}

The cerebral cortex consists of different functional domains that process distinct types of cortical information. These cortical re-

Received Jan. 3, 2017; revised Aug. 26, 2017; accepted Sept. 1, 2017.

Author contributions: Y.I. and H.T. designed research; Y.I., M.J.Y., S.M.S., A.S., and Y.H. performed research; Y.I., M.J.Y., and H.T. analyzed data; Y.I., M.J.Y., and H.T. wrote the paper.

This work was supported by Citizens United for Research in Epilepsy (CURE) and the Max Planck Society. We thank Dr. Joshua R. Sanes for sharing cadherin-6-CreER mice, Dr. Anirban Paul for helpful advice on manual cell collection, and Dr. Z. Josh Huang for critical reading of the manuscript.

The authors declare no competing financial interests.

*Y.I. and M.J.Y. contributed equally to this work.

Correspondence should be addressed to Hiroki Taniguchi, Max Planck Florida Institute for Neuroscience, Development and Function of Inhibitory Neural Circuits, One Max Planck Way, Jupiter, FL 33458. E-mail: hiroki.taniguchi@mpfi.org. gions share a prototypic network containing common cell types and circuit motifs, but establish unique circuit organization by modifying these cardinal components (Huang, 2014; Harris and Shepherd, 2015). Excitatory pyramidal neurons (PNs) and GABAergic inhibitory interneurons (INs) are the major cellular components in cortical circuits. Multiple canonical IN types defined by morphological, physiological, and neurochemical properties play a critical role in shaping PN activity (Klausberger and Somogyi, 2008; Kepecs and Fishell, 2014). Therefore, characterizing region-specific IN phenotypes and circuit organization is 
key to understanding the structural basis for functional specialization of cortical domains.

The neocortex [e.g., the medial prefrontal cortex (mPFC) and the somatosensory cortex] and the allocortex (e.g., the hippocampus and the piriform cortex) are two broad, functionally distinct cortical domains. The neocortex typically comprises six layers, among which excitatory PNs occupy layer 2 (L2) to L6. Clonal neocortical PNs are aligned radially and form synapses preferentially with each other, exhibiting a columnar organization (Yu et al., 2009). In contrast, the hippocampus contains a single layer of PNs in the CA regions. Clonally related hippocampal PNs are organized into horizontal not vertical clusters (Xu et al., 2014). Unlike neocortical PNs, these sister PNs rarely develop synapses with each other, but rather receive common synaptic inputs preferentially from neighboring fast-spiking INs (Xu et al., 2014). Such prominent differences in circuit organization between hippocampal and neocortical PNs imply corresponding variations of IN circuits that meet region-specific computational requirements.

Recent studies have shown that hippocampal oriens-lacunosum moleculare (O-LM) cells contain two subpopulations that are recruited differentially during hippocampal gamma oscillations, one of which is modified by serotonergic tone (Chittajallu et al., 2013), whereas Martinotti cells, neocortical counterparts of O-LM cells, do not contain a serotonin-responsive subpopulation. Likewise, although anatomical and functional differences are unknown, the majority of hippocampal neurogliaform cells (h-NGCs) strongly express neuronal nitric oxide synthase (nNOS), whereas neocortical NGCs (nc-NGCs) show weak expression of nNOS (Tricoire et al., 2010). These findings support the idea that canonical IN types could have "regional variants", contributing to the specific functions of distinct cortical domains. However, the extent of phenotypic variations in regional IN variants is not well characterized. Furthermore, it is unknown whether such regional variations of canonical IN phenotypes are shaped by local cellular environment or intrinsically specified.

The chandelier cell (ChC) (axo-axonic cell) displays unique and uniform axonal geometry with many prominent vertical branches containing strings of synaptic boutons aligned along axon initial segments (AISs) of PNs (Jones, 1975; Szentágothai, 1975; Somogyi, 1977). The striking stereotypy and precision of their innervation pattern make ChCs an ideal model with which to compare phenotypes of regional IN variants. We showed recently that the medial ganglionic eminence (MGE) during late gestation [embryonic day 15 (E15) to E18] predominantly produces neocortical ChCs (ncChCs) (Taniguchi et al., 2013). However, terminal phenotypes and birth timing of hippocampal ChCs (h-ChCs) compared with ncChCs remained unclear because there was no reliable and efficient strategy with which to target them.

In this study, we identify Cadherin-6 (Cdh6) as a reliable marker for ChCs and use Cdh6-CreER knock-in mice (Kay et al., 2011) to characterize neurochemical marker expression, axonal/synaptic organization, and the temporal origin of h-ChCs. We further test whether terminal phenotypes of h-ChCs and nc-ChCs are shaped by cellular milieus in distinct cortical regions. We demonstrate that h-ChCs and nc-ChCs appear to have distinct temporal origins, but their unique axonal patterns and neurochemical marker expression are regulated by extrinsic mechanisms.

\section{Materials and Methods}

Studies. All studies were approved by the Max Planck Florida Institute for Neuroscience Institutional Animal Care and Use Committee.

Mice. Heterozygous Nkx2.1-CreER knock-in mice (Taniguchi et al., 2011; Taniguchi et al., 2013) were bred to homozygous Cre-responsive
loxP-STOP-loxP (LSL)-RFP (Ai14) reporter mice (Madisen et al., 2010) to obtain Nkx2.1-CreER;Ai14/+. To get Nkx2.1-CreER;Ai14/Ai14 mice. Nkx2.1-CreER;Ai14/+ mice were further bred to Ai14/Ai14 mice. Cdh6CreER knock-in mice were generated in the laboratory of Dr. Joshua Sanes and provided as a generous gift (Kay et al., 2011). Dlx5/6-Flp mice (Miyoshi et al., 2010) were bred to the homozygous Cre/Flp dualresponsive frt-STOP-frt (FSF)-LSL-RFP mice (Ai65) (Madisen et al., 2015) to obtain Dlx5/6-Flp;Ai65/+ mice. To get Dlx5/6-Flp;Ai65/Ai65 mice, Dlx5/6-Flp;Ai65/+ mice were further crossed with Ai65/Ai65 mice. Parvalbumin (PV)-ires-Cre, Somatostatin (SOM)-ires-Cre, and vasoactive intestinal peptide (VIP)-ires-Cre knock-in mice (Hippenmeyer et al., 2005; Taniguchi et al., 2011) were maintained as homozygous. Both males and females were used for analyses.

Single cell collection. Nkx2.1-CreER;Ai14/Ai14 males were crossed with Swiss Webster (SW) females and the pregnant dams were injected with tamoxifen (Tmx) at a dose of $3 \mathrm{mg} / 30 \mathrm{~g}$ of body weight at E17 to induce CreER activity in their offspring. Nkx2.1-CreER;Ai14/+ pups were identified by RFP expression in the lung at postnatal day 0 (P0) or P1 under a fluorescence dissecting stereomicroscope. Fresh brains were taken from P5 pups and 300- to $400-\mu \mathrm{m}$-thick slices were prepared using a tissue chopper (Intracell Technology). Cortical strips containing layer $2 / 3$ (L2/3) cells were dissected from the medial prefrontal and cingulate cortices and dissociated into individual cells in Hibernate E medium (Invitrogen) containing Pronase E (Sigma-Aldrich, $1 \mathrm{mg} / \mathrm{ml}$ ) and DNaseI (Thermo Fisher Scientific, $5 \mathrm{U} / \mathrm{ml}$ ) at $37^{\circ} \mathrm{C}$ for $10 \mathrm{~min}$. After washing with Hibernate E medium once, cells were spread in $35 \mathrm{~mm}$ dishes. Fifty $\mathrm{RFP}^{+}$cells were picked up using a glass micropipette (Warner Instruments, \#203-776-064) pulled with a micropipette puller (Sutter Instrument, \#P-1000) under a fluorescence dissecting stereomicroscope and collected directly into RNA extraction medium (TaKaRa, \#3734).

RNA extraction, reverse transcription, and cDNA amplification. RNA extraction from dissociated cells and cDNA amplification were performed according to the CellAmp Whole Transcriptome Amplification kit manual (TaKaRa, \#3734). The amplified cDNA was diluted $1 / 10$ for the following PCR analyses.

PCR. PCR for classic cadherin genes using the Light-Cycler system (Bio-Rad) was performed with Ex Taq hot start polymerase (TaKaRa, \#RR006A). A total of $1 \mu \mathrm{l}$ of the amplified cDNA was used for PCRs and the conditions were as follows: $20 \mathrm{~s}$ for denaturation at $98^{\circ} \mathrm{C}, 20 \mathrm{~s}$ for annealing at $60^{\circ} \mathrm{C}, 20 \mathrm{~s}$ for extension at $72^{\circ} \mathrm{C}$ repeated for 32 cycles. The sense and antisense primers for the $C d h$ and Gapdh genes are shown in Table 1.

Immunohistochemistry (IHC). Mice were perfused with saline and $4 \%$ PFA in pH 7.4 PBS. Brains were excised and postfixed in 2\% PFA overnight at $4^{\circ} \mathrm{C}$. Sixty- $\mu \mathrm{m}$-thick coronal or sagittal sections were prepared using an automated vibratome (Leica, \#VT1200 S). All sections were pretreated with $0.5 \%$ Triton X-100/PBS for $10 \mathrm{~min}$ at room temperature before blocking in $10 \%$ normal donkey serum/0.1\% Triton X-100/PBS for $1 \mathrm{~h}$ and overnight incubation with primary antibodies at $4^{\circ} \mathrm{C}$ in blocking solution. After washing in PBS, sections were incubated with secondary antibodies in blocking solution for $2 \mathrm{~h}$ before washing and mounting in DAPI-containing media (DAPI Fluoromount-G; Southern Biotech, 0100-20).

The following primary antibodies were used in this study: alkaline phosphatase-conjugated sheep anti-DIG (1:2000; Roche, \#11093274910), mouse monoclonal anti-BrdU (1:500; BD PharMingen, \#555627), rabbit polyclonal anti-RFP (1:800; Rockland, \#600-401-379), mouse monoclonal anti-AnkG (1:500; NeuroMab, \#75-146), rabbit polyclonal anti-PV (1:1000; Swant, P27), guinea pig polyclonal anti-PV (1:2000; Swant, GP72), rat monoclonal anti-SOM (1:250; Millipore, MAB354), rabbit polyclonal anti-nNOS (1:500; Thermo Fisher Scientific, \#61-7000), rabbit polyclonal anti-VIP (1:500; Immunostar, \#20077), and rabbit polyclonal anti-calretinin (CR) (1:1000; Swant, \#7697). The following secondary antibodies were used: donkey antibodies conjugated to DyLight 405, Alexa Fluor 488, Cy3, or Cy5 (Jackson ImmunoResearch, $1: 1000)$ and donkey biotinylated anti-rabbit IgG (1:500; Jackson ImmunoResearch, \#711-065-152).

Image acquisition and $3 D$ reconstruction. Confocal images were acquired using a confocal microscope (Zeiss CLSM 780 or 880 or $20 \times$ Plan 
Table 1. PCR primers for RT-PCR

\begin{tabular}{|c|c|c|}
\hline Gene & Primer & Sequence \\
\hline \multirow[t]{2}{*}{ Cdh1 } & Sense & 5'-GCTGGCCGATTTAAACCCAA-3' \\
\hline & Antisense & 5'-CTGGCTGTCCTAGAATTCGCT-3' \\
\hline \multirow[t]{2}{*}{ Cdh2 } & Sense & 5'-CCACCTCGCTGTAAAAATGGTG-3' \\
\hline & Antisense & 5' -CACATGTTCCGAGTTCTCTGC-3' \\
\hline \multirow[t]{2}{*}{$C d h 3$} & Sense & 5'-ATTGATTGCTCCACGCCCAT-3' \\
\hline & Antisense & 5'-TCCATCACCCATGAGCCTTC-3' \\
\hline \multirow[t]{2}{*}{ Cdh4 } & Sense & 5'-GGGACGCATCTTGCTTTTCC-3' \\
\hline & Antisense & 5'-TGTGAACACGTCAGACTCCG-3' \\
\hline \multirow[t]{2}{*}{ Cdh5 } & Sense & 5'-TGTGGCCTCTCTGCATCTCT-3' \\
\hline & Antisense & 5'-AGTTGAAGGCACATTTCCGC-3' \\
\hline \multirow[t]{2}{*}{ Cdh6 } & Sense & 5'-TATGCCACCCTTTGAAGACC-3' \\
\hline & Antisense & $5^{\prime}$-CGAACTAGGCGCAAGGATAG-3' \\
\hline \multirow[t]{2}{*}{ Cdh7 } & Sense & $5^{\prime}$-CCACTTCTGGGACAAAAGGAG-3' \\
\hline & Antisense & 5'-TGTGGTCAGAGAAATCCCTTG-3' \\
\hline \multirow[t]{2}{*}{ Cdh8 } & Sense & 5'-TCAGAGAAACTCCTGTATTGTTTCC-3 \\
\hline & Antisense & $5^{\prime}$-CCACAGTGAGATTTCATTGCAC-3' \\
\hline \multirow[t]{2}{*}{ Cdh9 } & Sense & 5'-AGATTGAGTGGCCTGTGTTGT-3' \\
\hline & Antisense & 5'-TAGGCAAAGAGGGTGAACAGG-3' \\
\hline \multirow[t]{2}{*}{ Cdh10 } & Sense & $5^{\prime}$-ACTGAAGGAGACCAAAACTACG-3' \\
\hline & Antisense & $5^{\prime}$-CGTTGAACATAACACAGGCG-3' \\
\hline \multirow[t]{2}{*}{ Cdh11 } & Sense & $5^{\prime}$-TGAAACACAGGGCACAAACAA-3' \\
\hline & Antisense & $5^{\prime}$-CAAAGTGAACTGGGAGGGAGT-3' \\
\hline \multirow[t]{2}{*}{ Cdh12 } & Sense & 5'-ACCCACAGGTCCTCTGTTTG-3' \\
\hline & Antisense & 5'-TTGAGATTGGGATTGCATGA-3' \\
\hline \multirow[t]{2}{*}{ Cdh15 } & Sense & 5'-GGCTGGCGGACATGTATG-3' \\
\hline & Antisense & $5^{\prime}$-CCATGCTGTTGACCCTCATAG-3' \\
\hline \multirow[t]{2}{*}{ Cdh18 } & Sense & 5'-ATGCAGAAGCCTTCCTGTC-3' \\
\hline & Antisense & 5'-TCGGAAATGATCAAGGGCTC-3' \\
\hline \multirow[t]{2}{*}{ Cdh22 } & Sense & 5' -GTCTTGAAGGTGTCAGATGGG-3' \\
\hline & Antisense & $5^{\prime}$-AGGCCCAGAGAAATGACATG-3' \\
\hline \multirow[t]{2}{*}{ Cdh24 } & Sense & 5'-GTATGGGGCCAAGGAGC-3' \\
\hline & Antisense & $5^{\prime}$-AAAGGAGGGTCATATTGGGC-3' \\
\hline \multirow[t]{2}{*}{ Gapdh } & Sense & 5' -CTTTGTCAAGCTCATTTCCTGG-3' \\
\hline & Antisense & 5'-TCTTGCTCAGTGTCCTTGC-3' \\
\hline
\end{tabular}

ApoChromat, numerical aperture: 0.8 ). 3D images were reconstructed semiautomatically from confocal $z$-stack images using the filament tracer in the IMARIS software followed by manual corrections.

Fluorescent in situ hybridization (FISH) and chromogenic ISH (CISH). ISH was performed as described previously (Watakabe et al., 2010) with slight modifications. Digoxigenin (DIG)-labeled single-strand riboprobes were synthesized using T7, T3, or SP6 RNA polymerase and DIG RNA-labeling mix (Roche). The sequence information for RNA probes is shown in Table 2. Except for CR ISH, two distinct probes were used simultaneously for each gene. Nkx2.1-CreER;Ai14/+ mice with Tmxinduced RFP were obtained as described in the section on single cell collection. To label PV-INs, SOM-INs, and VIP-INs specifically with RFP, homozygous $P V$-ires-Cre, SOM-ires-Cre, or VIP-ires-Cre mice were crossed with Ai14/Ai14 mice. Cdh6-CreER;Dlx5/6-Flp;Ai65/+ mice were obtained by crossing Cdh6-CreER females with Dlx5/6-Flp;Ai65/Ai65 males. The pups were administered Tmx ( $2 \mathrm{mg} / 30 \mathrm{~g}$ of body weight) intraperitoneally at P5 to induce medium levels of recombination and ChC labeling. P21 mice were perfused and the tissue was processed as described above. Sixty- $\mu$ m-thick sections prepared from whole brains were treated with proteinase $\mathrm{K}(40 \mu \mathrm{g} / \mathrm{ml}$ for $30 \mathrm{~min}$ at room temperature) and hybridized at $63^{\circ} \mathrm{C}$ with DIG-labeled antisense riboprobes in a hybridization solution consisting of $40 \%$ formamide, $20 \mathrm{~mm}$ Tris- $\mathrm{HCl}$, pH 7.5, $600 \mathrm{~mm} \mathrm{NaCl}, 1 \mathrm{~mm}$ EDTA, 10\% dextran sulfate, $200 \mathrm{mg} / \mathrm{ml}$ yeast tRNA, and $1 \times$ Denhardt's solution. The sections were washed twice in $1 \times$ SSC (Invitrogen) containing $50 \%$ formamide and once in $0.1 \times$ SSC at $63^{\circ} \mathrm{C}$, followed by 2 washes with $0.1 \mathrm{M}$ maleic buffer, $\mathrm{pH} 7.5$, containing $0.1 \%$ Tween 20 and $150 \mathrm{~mm} \mathrm{NaCl}$. Then, those sections were incubated with anti-DIG antibodies conjugated with alkaline phosphatase for $2 \mathrm{~h}$ at room temperature, followed by 3 washes in PBT solution (PBS containing $0.1 \%$ Triton $\mathrm{X}-100)$. Sections were incubated with rabbit polyclonal
anti-RFP antibodies overnight at $4^{\circ} \mathrm{C}$. After washing 3 times in PBT, sections were incubated with biotinylated anti-rabbit IgG antibodies overnight at $4^{\circ} \mathrm{C}$ followed by 3 washes in PBT. The sections were then incubated with Alexa Fluor 488-streptavidin (1:1000; Jackson ImmunoResearch, \#016-540-084) to visualize $\mathrm{RFP}^{+}$cells for $2 \mathrm{~h}$ at room temperature. The native red fluorescent signals from RFP were completely bleached after this treatment. For FISH, color development for mRNA expression was performed in the presence of HNPP/FastRed solution (Roche, $100 \mu \mathrm{g} / \mathrm{ml} \mathrm{HNPP,} 250 \mu \mathrm{g} / \mathrm{ml}$ FastRed) for $1 \mathrm{~h}$ at room temperature. The sections were washed $1 \mathrm{~min}$ in PBS and mounted with CC/ Mount tissue mounting medium (Sigma-Aldrich, \#C9368). Confocal images were taken immediately after color development. For the CISH color development, sections were incubated in solution of 4-nitro blue tetrazolium chloride (Roche, $50 \mu \mathrm{g} / \mathrm{ml}$ ) and 5-bromo-4-chloro-3-indolylphosphate (Roche, $175 \mu \mathrm{g} / \mathrm{ml}$ ) overnight in the dark at room temperature.

Characterization and quantification of neurochemical marker expression in ChCs labeled in Cdh6-CreER;Dlx5/6-Flp;Ai65/+ mice. Cdh6-CreER; Dlx5/6-Flp;Ai65/+ mice were obtained as described above. The pups were administered $\operatorname{Tmx}(2 \mathrm{mg} / 30 \mathrm{~g}$ of body weight) intraperitoneally at P5 to induce medium levels of cell labeling. The following sets of antibodies were used: (1) rabbit polyclonal anti-PV and mouse monoclonal anti-AnkG with Alexa Fluor 488-donkey anti-rabbit and Cy5-donkey anti-mouse secondary antibodies; (2) rat monoclonal anti-SOM, rabbit polyclonal anti-RFP, and mouse monoclonal anti-AnkG with Cy5donkey anti-rat, Cy3-donkey anti-rabbit, and Alexa Fluor 488-donkey anti-mouse secondary antibodies; (3) rabbit polyclonal anti-nNOS and mouse monoclonal anti-AnkG with Alexa Fluor 488-donkey anti-rabbit and Cy5-donkey anti-mouse secondary antibodies; (4) rabbit polyclonal anti-VIP and mouse monoclonal anti-AnkG with Alexa Fluor 488donkey anti-rabbit and Cy5-donkey anti-mouse secondary antibodies; (5) rabbit polyclonal anti-CR and mouse monoclonal anti-AnkG with Alexa Fluor 488-donkey anti-rabbit and Cy5-donkey anti-mouse secondary antibodies; and (6) rabbit polyclonal anti-CR, guinea pig polyclonal anti-PV, and mouse monoclonal anti-AnkG with Alexa Fluor 488-donkey anti-rabbit, Cy5-donkey anti-guinea pig, and DyLight 405donkey anti-mouse secondary antibodies. To count cells that coexpress RFP and neurochemical markers, an epifluorescence microscope with a $40 \times$ objective lens was used. Representative images showing colocalization of RFP and neurochemical markers were taken by confocal microscopy. To differentiate h-ChCs from non-ChCs, confocal images of native RFP signals, DAPI signals, and AISs stained with anti-AnkG antibodies were acquired. Cells displaying axonal arbors restricted in the dorsal half of the stratum pyramidale (SP) layer and varicosities aligned to AISs were considered h-ChCs.

BrdU labeling. Cdh6-CreER males were crossed with Dlx5/6-Flp;Ai65/ Ai65 females. Timed pregnant animals were injected once intraperitoneally with BrdU (50 mg/kg body weight) (BD PharMingen, \#550891) at the indicated embryonic ages. Cdh6-CreER;Dlx5/6-Flp;Ai65/+ pups were induced at P5 with Tmx at a dose of $2 \mathrm{mg} / 30 \mathrm{~g}$ of body weight. P21 mice were perfused and brains were excised and postfixed as described above. Brain sections were incubated in $2 \mathrm{~N} \mathrm{HCl}$ for $30 \mathrm{~min}$ at room temperature, washed 3 times for $10 \mathrm{~min}$ in PBS, and incubated with mouse monoclonal anti-BrdU and rabbit polyclonal anti-RFP in PBS containing $10 \%$ normal donkey serum overnight at $4^{\circ} \mathrm{C}$. After washing with PBS, sections were incubated with Cy3-donkey anti-rabbit and Alexa Fluor 488-donkey anti-mouse for $2 \mathrm{~h}$ at room temperature.

Quantification of cellular distribution, axonal expansion, and the number of AISs innervated by a single ChC. Cdh6-CreER;Dlx5/6-Flp; Ai65/+ mice were obtained as described above. For the quantification of distribution of $\mathrm{RFP}^{+} \mathrm{h}$-ChCs, $\mathrm{P} 5$ pups were administered Tmx at either a high dose $(6 \mathrm{mg} / 30 \mathrm{~g}$ of body weight $)$ or a medium dose $(2 \mathrm{mg} / 30 \mathrm{~g}$ of body weight) intraperitoneally. For the quantification of axonal expansion and the number of AISs innervated by a single ChC, P5 pups were administered Tmx at a low dose $(0.5 \mathrm{mg} / 30 \mathrm{~g}$ of body weight $)$ intraperitoneally to induce sparse recombination and ChC labeling. P21 mice were perfused and the coronal brain sections were processed and immunostained with anti-RFP and anti-AnkG antibodies as described above.

To assess the extent of anteroposterior (A-P) axonal expansion, spatially isolated, nonoverlapping h-ChCs from the SP were identified. Be- 
Table 2. RNA probes for ISH

Probe Sequence

Cdh4-1

CTACAACGGCTCTGTGGATGAGGGCTCCAAGCCAGGTACATATGTGATGACCGTCACAGCCAACGATGCAGATGATAGCACCACAGCCAATGGCATGGTGAGGTACAGAATTGTCACCCAGACACCCC AGAGCCCATCCCAGAATATGTTCACCATCAACAGTGAAACAGGGGACATCGTGACCGTGGCAGCAGGCCTGGACAGAGAGAAAGTCCAGCAGTACACCGTCATCGTCCAGGCCACTGACATGGAAG GAAACCTTAATTATGGTCTCTCGAACACAGCCACTGCCATCATCACGGTGACAGACGTAAATGACAACCCTCCGGAATTCACCACAAGCACATTTGCAGGAGAGGTTCCTGAGAACCGTATAGAG ACAGTAGTAGCCAACCTCACGGTGATGGACCGAGACCAGCCCCACTCACCCAACTGGAACGCCGTCTACCGAATCATAAGTGGGGACCCCTCTGGGCACTTCAGTGTCCGCACAGACCCCGTGACCA ATGAGGGCATGGTCACCGTGGTGAAGGCAGTGGACTATGAGCTGAACCGTGCCTTCATGCTGACCGTAATGGTGTCCAACCAGGGGCCCCTGGCCAGTGGGATCCAGATGTCCTTCCAGTCCACAGCA GGGGTAACCATCTCTGTCACCGATGTCAACGAGGCCCCCTACTTCCCCTCCAACCACAAACTGATCCGCCTGGAAGAGGGTGTGCCCGCTGGGACAGCACTCACCACTTT

Cdh4-2 ACAAAGCAGCTGCTCATCGACCCTGAGGATGACGTGAGGGACAACATCCTGAAGTACGATGAAGAGGGCGGTGGCGAGGAGGACCAAGACTACGACCTCAGCCAGCTGCAACAGCCAGAAGCCATG GAGCATGTGCTGAGCAAAACTCCTGGTGTGCGGCGGGTGGATGAACGGCCAGTAGGTGCTGAACCCCAGTACCCAGTCAGGCCTGTGGTGCCACACCCAGGAGACATTGGAGACTTCATTAATGAGG GACTCCGAGCTGCTGACAATGACCCCACCGCACCCCCCTACGACTCCCTGCTAGTCTTCGACTATGAAGGCAGCGGTTCTACTGCGGGCTCTGTCAGCTCCCTAAACTCCTCCAGCTCCGGGGATCAAGA TTACGACTACTTAAATGACTGGGGGCCCCGGTTCAAGAAGCTGGCGGACATGTATGGGGGTGGGGAGGAGGACTAACCAACCTCACCACCAATGCAAGAAGGGCACTGGAGGCGAGCAGCAGAACT GAGCCGAGGTGCCAGCGCCGTCTGGTGTCGAGAGGTCCCTCCCCGCTGCCGTCCCCCATGTGGAGCTCTGCAGTATGGACATAGGCCACCGGGCACCCATCATCACTGCGGCATCTCGGTAG CCACAGCCACGTACTGCGAAGGGAGAGCCAGAGGCACAGCCCTAACTTGAA

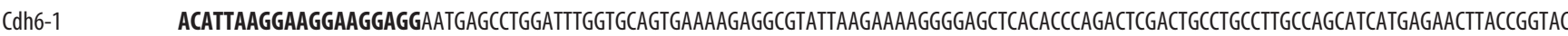
TTCTTGCTGCTCTTTTGGGTCGGCCAGCCCTACCCAACTTTCTCAAACCCATTATCTAAAAGGACTAGTGGCTTCCCAGCAAAGAGGAAAGCCCTGGAGCTCTCTGCAAACAGCAGGAATGAGCTGA GCCGTTCGAAAAGGAGTTGGATGTGGAATCAGTTCTTCCTCCTGGAGGAATACACGGGATCCGATTATCAGTACGTGGGCAAGTTACATTCAGACCAGGATAGAGGAGATGGATCACTTAAATAT ATCCTTTCAGGAGATGGAGCGGGCGATCTCTTCATTATCAATGAGAACACAGGCGACATACAGGCCACCAAGAGGCTGGACAGGGAAGAAAAACCTGTTTACATCCTTCGAGCTCAAGCTGTCAAC AGAAGGACAGGGAGACCCGTCGAGCCTGAGTCTGAATTCATCATCAAGATCCACGACATCAATGACAATGAGCCAATATTCACCAAGGACGTTTACACAGCCACAGTCCCGGAGATGGCTGATGT TGGCACATTTGTGGTCCAAGTCACGGCGACTGATGCTGACGACCCAAC

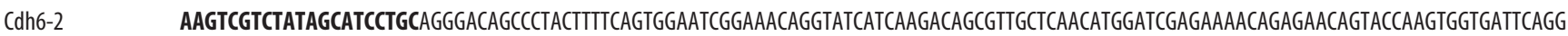
CCAAGGACATGGGGGGCCAGATGGGAGGACTGTCGGGGACTACGACCGTGAACATCACGCTGACAGATGTCAATGACAACCCACCCCGTTTCCCCCAGAGTACCTACCAGTTTAAGACCCCCGAGTC CTCTCCACCGGGAACGCCAATTGGCAGGATCAAAGCCAGTGATGCCGATGTGGGAGAAAATGGGGAGATCGAGTACAGCATCACTGACGGTGAGGGACACGAGATGTTTGATGTCATCACCGACC AGGAAACCCAGGAAGGGATCATAACTGTCAAAAAGCTCTTGGATTTTGAGAAGAAGAAGGTGTACACCCTCAAGGTGGAAGCCTCCAATCCCCACGTCGAACCCCGATTTCTCTACCTGGGTCCCTTC AAAGACTCGGCCACGGTGAGAATCGTGGTGGACGATGTGGACGAACCTCCTGTCTTCAGCAAACTGGCCTACATCCTACAGATACGGGAGGATGCCCGGATAAATACGACCATAGGCTCTGTCGCAG CTCAGGATCCTGACGCTGCCAGGAATCCTGTCAAGTATTCTGTGGATAGACACACAGATATGGACAGGATATTCAACATTGATTCTGGAAATGGTTCGATTTTTACATCAAAAC TTCTCGACCGGGAAACCCTGCTGTGGCACAACATCACAGTGATCGCAACGGAGATTAATAACCCAAAGCAAAGCAGCCGCGTTCCTCTATATATTAAAGTTCTCGACGTCAACGAC

Cdh9-1 TGGGAACAGTGCTAAAGTGGTCTACAGCATTCTGCAAGGGCAGCCATACTTTTCAGTGGACCCGGAATCAGGCATAATAAAGACTGCATTGCCAGACATGAGCAGAGAAAACAAAGAGCAGTACCAA GTTGTTATTCAGGCTAAGGACATGGGTGGCCAGATGGGAGGCCTCTCTGGCACCACCACAGTGAACATCACCCTAACAGATGTCAACAACAACCCTCCTCGGTTCCCACAGAGCACTTATCAGTTTAA TTCTCTGGAGTCGGCACCTCTTGGAACTCATCTTGGAAGGATAAAAGCCAATGACCCAGACATGGGGGAGAACGCCGAGCTGGAATATAGCATTGCAGAAGGAGAAGGATCAGACATGTTTGATGT GATCACTGACAAAGATACACAGGAAGGGATCATAACTGTCAAACAGAATTTAGATTTTGAAAAGAAAATGTTGTACACTTTAAGAGTGGATGCAAGTAATACCCACCCTGATCCTCGATTCTTACAC CTTGGACCTTTCAAAGACTCAGCCATGGTTAAGATATCTGTGGAAGATGTAGATGAGCCCCCTGTGTTCAGTAAGCTCTCTTACTTGATGGAAGTTGATGAAGATGTGAAGGAGGGGAGCATCATCG GACAAGTCACAGCATATGACCCAGATGCCATGAACAACATAATAAAATACTCTGTGGACCGCCATACTGATATGGACCGAGTTTTCAGTATTCACTCAGAAAATGGTTCTATCTTCACTCTGAAACCCCTGGA

Cdh9-2 CGGAAGCAAGAGAAGACAGTAAACTTAGAAGAGATGTCATGCCTGAAACTATTTTTCAGATAAGGAGGACAGTACCCCTCTGGGAAAATATTGACGTACAAGATTTTATACACCGGAGACTGAAAG AAAACGACTCAGACCCAAGTGCACCGCCCTACGACTCCCTGGCCACTTATGCCTATGAAGGGAATGATTCTGTTGCCAATTCTCTCAGCTCCTTAGAATCTCTCACAGCTGATTGCAACCAGGATTATG ATTACCTTAGCGACTGGGGACCTCGGTTCAAAAAACTCGCAGAAATGTATGGGGGTAACGACAGTGATCTGAACTGAATCCTATATGACTTCATCAACATTAGTAGAAACAGTATCTTCAATACCAG ATTGAGTGGCCTGTGTTGTCCCTTTTTGGAGGAAAATTTTAAAATAACAACTCCAAACAATACATAAGTGTTGTCCTAGTAAGGGTTTGCTTAATCAGTAAGTTTCTGTGAATGAGTATGAATGATA TAGATTTTAAAACAGTAATAATAACCTGTTCACCCTCTTTGCCTAATAAGCTTGGAAAAATATATCACATTAATAATCAATAAAAATTCTTGAAAGGCTTTTTGTGCCTTGTCTTAGTATAGGAACTT TATAAATGITTTCTTAACTGATTGTCAGTCACATATACTATGAAACGAAACATTGTGCAACTGCTTTGTAAATTAATATGAAAGAAAATATACCTAATGAAATAGGAGTGACTATTACTGCCAT GCCAATGAGCTCAAGGGATTCCTGTCTGACCTCCTGAAGAAGGCCAACAGGCCCTATGATGAACCTAAGCTCCAGGAGTACACCCAGACCATACTACGGATGTTTGACTTAAATGGAGATGGCAAATT GGGTCTCTCAGAGATGTCTAGACTCTTGCCTGTACAAGAGAACTTCCTGCTGAAATTTCAGGGTATGAAGCTGACCTCAGAAGAGTTCAATGCCATCTTCACATTTTATGACAAGGATGGAAGCGGCT ATATTGATGAGAATGAACTGGACGCCCTCCTGAAGGATCTGTATGAGAAGAACAAGAAGGAGATGAACATCCAACAGCTCACCACCTACAGGAAGAGTGTCATGTCCTTGGCCGAGGCAGGGAAG CTCTACAGAAAGGACCTGGAGATTGTGCTCTGCAGTGAGCCCCCCGTGTAAAGGGGTGAAGGGACAGGGGCTGCTTCTGCGCCTCCCTTGAACCCCGCCCCCGCTGTCCTGACTCTCTTGACACTCCT TCCCAGACCTCCCCACCCCCTGCCACCTGCACACACCAGCCTGTGGATCTGGAAAGGAGAGATGGAGAGAGGGTGGTTGGTAGGGTTCCTTAGGCCTGATAGACAGTTGTGCCTGCGTTGGGTCACGG TTGGTGGGCGGGGCTGCAGGGGAAGCTTCTGTCGTCTCCGCTGCGATGCATGAGTTCCTTCGCTGTATGATTTAGGCTTCTGAGTCCCACAGAGTGGACTCCTICCTC

Primer sequences are shown as bold.

cause sections are normally compressed to $30-40 \mu \mathrm{m}$ after mounting on slides, we calculated the theoretical value of A-P axonal expansion in a following way. First, we determined the total number of coronal sections containing axonal RFP signals for each cell. The number of central sections (e.g., sections 2 through 11 for a cell with axons that span 12 coronal sections) was counted and the extent of an arbor fragment within the central sections was obtained by multiplying $60 \mu \mathrm{m}$ by the number. After this, confocal $z$-stack images of DAPI and RFP-labeled axons in the terminal sections (sections 1 and 12 in the above example) were taken to determine the thickness of sections and the lengths of arbor fragments on slides. The proportion of an arbor length to the thickness of a section was calculated and then multiplied by $60 \mu \mathrm{m}$ to obtain the theoretical lengths of arbor fragments in terminal sections. These two theoretical lengths were then added to the extent of an arbor fragment within central sections to determine the approximate $\mathrm{A}-\mathrm{P}$ extent of a whole $\mathrm{ChC}$ arbor. The same was done for nc-ChCs in Cdh6-CreER;Dlx5/6-Flp;Ai65/+ animals induced with $2 \mathrm{mg} / 30 \mathrm{~g}$ Tmx induction. Mediolateral (M-L) axonal arborization was assessed by averaging the distances of the horizontal extent of axonal RFP signals in the three central coronal sections with the widest arbors (the horizontal axis was defined as the line parallel to the SP cell layer for h-ChCs or the pia for nc-ChCs).

The number of AISs innervated by a single $\mathrm{ChC}$, which corresponds to the number of $\mathrm{PNs}$ innervated by a single $\mathrm{ChC}$, was estimated by dividing the number of total varicosities apposed to AISs stained with anti-AnkG antibodies by the average number of varicosities per AIS. For quantification of varicosities, the spots tool in the IMARIS was used: after automatic image thresholding, spots with diameter of smaller than $3 \mu \mathrm{m}$ in $x-y$ and $3.5 \mu \mathrm{m}$ in $z$ were selected as varicosities. AnkG signals representing AISs were 3D rendered using the IMARIS surface tool: after automatic thresholding of AnkG images, objects that had bounding boxes larger than $10 \mu \mathrm{m}$ in height and $2 \mu \mathrm{m}$ in width were selected. The threshold value $(10 \mu \mathrm{m} \times 2 \mu \mathrm{m})$ was determined based on the size of a bounding box for the smallest AIS stained with anti-AnkG antibodies. Varicosities apposed to the rendered AISs were counted to calculate the total number of putative cartridge varicosities per ChC. To get the average number of varicosities per cartridge, varicosities apposed to each fully isolated AnkG-stained AIS were counted and averaged (5 AISs for each cell). We confirmed spatial isolation of AnkG-stained AISs by eye using 
$z$-stack confocal images on ZEN (Zeiss). These AnkG-stained structures were traced manually to measure the length.

Transplantation. Nkx2.1-CreER;Ai14/Ai14 males were crossed with SW females to obtain Nkx2.1-CreER;Ai14 embryos. Timed pregnant SW mice were deeply anesthetized at E16-E18 using isoflurane. After cervical dislocation, the uterus was dissected and kept in DPBS (GE Healthcare). For the transplantation of nc-ChCs into the hippocampus (hereafter called neocortex-to-hippocampus transplantation), pregnant females were administered Tmx ( $3 \mathrm{mg} / 30 \mathrm{~g}$ of body weight) at E16 and brains were taken from E17 embryos in Hibernate E buffer (Thermo Fisher Scientific). The brains were cut into 400 - $\mu \mathrm{m}$-thick sections using a tissue chopper (Intracell Technology) from which MGE tissues were dissected. For the transplantation of h-ChCs into the neocortex (hereafter called hippocampus-to-neocortex transplantation), pregnant females were administered Tmx ( $3 \mathrm{mg} / 30 \mathrm{~g}$ of body weight) at E12 and brains were taken from E16-E18 embryos in Hibernate E buffer. Hippocampal tissues were dissected from the brains in Hibernate E buffer. Tissues collected in $1 \mathrm{ml}$ of Hibernate E buffer were incubated with $0.25 \%$ Trypsin (Thermo Fisher Scientific) and DNase I (Thermo Fisher Scientific, $5 \mathrm{U} / \mathrm{ml}$ ) at $37^{\circ} \mathrm{C}$ for $10 \mathrm{~min}$ followed by the addition of FBS (10\%, final concentration). After centrifuging for $5 \mathrm{~min}$ at $500 \times g$, cells were resuspended in Hibernate $\mathrm{E}$ buffer. P1-P3 SW mice were anesthetized on ice for $2 \mathrm{~min}$ and the absence of pain perception was ensured. Then, 15,000-20,000 cells were injected bilaterally at $0.2 \mathrm{~mm}$ lateral and $0.2 \mathrm{~mm}$ anterior of bregma at a depth of 250-400 $\mu \mathrm{m}$ for hippocampus-to-neocortex transplantation using pulled glass pipettes in combination with a stereotaxic apparatus (Kopf Instruments) and a picospritzer (Parker). For neocortex-tohippocampus transplantation, cells were injected at $0.8 \mathrm{~mm}$ lateral and $0.7 \mathrm{~mm}$ posterior of bregma at a depth of $750-900 \mu \mathrm{m}$. The incision was closed with vet bond (Patterson Veterinary) and the pups were placed on a heat plate at $37^{\circ} \mathrm{C}$ until fully recovered. In the case of neocortex-tohippocampus transplantation, we found $1-2 \mathrm{ChCs}$ of $\sim 20$ isolated $\mathrm{RFP}^{+}$ cells per brain. In the case of hippocampus-to-neocortex transplantation, RFP cells tended to form an aggregate consisting of 30-40 cells at the injection site. However, we could find 1-2 ChCs among $\sim 40$ isolated cells per brain.

Statistical analysis. All statistics were done using Prism 6.0 software (GraphPad). Comparisons were done by two-tailed Student's $t$ test or one-way ANOVA with Tukey post hoc testing. All graphs and results show group mean \pm SEM.

\section{Results \\ Cdh6 is expressed preferentially in nc-ChCs labeled in Nkx2.1-CreER;Ai14/+ mice}

Our previous study demonstrated that Nkx2.1-CreER knock-in mice provide efficient genetic access to nc-ChCs (Taniguchi et al., 2013). However, this approach failed to target h-ChCs (data not shown; $0 \%, 100$ hippocampal INs, $n=3$ mice). We reasoned that the first step to targeting h-ChCs would be to identify reliable markers for ChCs.

Classical cadherins (hereafter referred to as cadherins) have been shown to play critical roles in multiple events in neural circuit construction such as cell migration, axon guidance, target recognition, and synapse formation (Takeichi, 2007). In particular, the expression of cadherins in both specific neuronal populations and their postsynaptic targets raised the hypothesis that cadherins mediate the formation of precise synaptic connectivity in neural circuits (Suzuki et al., 1997; Inoue et al., 1998). In fact, a recent study demonstrated that Cdh6 is essential for synaptic partner matching between a subset of retinal ganglion cells and their retinorecipient targets in the brain that mediate non-image-forming visual functions (Osterhout et al., 2011). The expression of distinct cadherins in different neuronal domains and types led us to hypothesize that a unique set of cadherins are expressed preferentially in ChCs.

To identify cadherins that are expressed in nc-ChCs, we performed a PCR-based screening combined with manual sorting of fluorescently labeled cells. We induced RFP expression in the MGE of Nkx2.1-CreER;Ai14/+ mouse embryos at E17 by administering Tmx to pregnant females, resulting in efficient labeling of nc-ChCs (Fig. 1A) (Taniguchi et al., 2013). Because the labeled nc-ChCs are most densely localized in L2 of the medial prefrontal and cingulate cortices (Taniguchi et al., 2013), we collected RFP ${ }^{+}$ cells from L2 of these cortical areas at P5 (Fig. 1B). Fifty cells from each litter were collected manually and three biological replicates were prepared. After extraction of mRNA, we conducted reverse transcription followed by cDNA amplification. We then performed a PCR screening using sets of primers that detect $16 \mathrm{cad}-$ herin genes. Because primers for $C d h 19$ and $C d h 20$ genes failed to detect PCR products when cDNAs prepared from a whole brain and a spinal cord were used as a template, we excluded these genes from the analysis. Our PCR screening detected Cdh4, Cdh6, and $C d h 9$, suggesting that young $\mathrm{RFP}^{+}{ }^{+} \mathrm{nc}-\mathrm{ChCs}$ obtained from Nkx2.1-CreER;Ai14/+ mice express a relatively small number of cadherin genes (Fig. 1C).

We then investigated whether these genes are expressed preferentially in $\mathrm{RFP}^{+}$nc-ChCs labeled in Nkx2.1-CreER;Ai14/+ mice compared with representative IN types including PV-expressing, SOM-expressing, and VIP-expressing INs. To this end, we performed FISH for Cdh4, Cdh6, and Cdh9 in P21 brain sections containing RFP-labeled nc-ChCs, PV-INs, SOM-INs, or VIPINs. As expected, all three cadherins were expressed in a large fraction of $\mathrm{RFP}^{+}$nc-ChCs [Figure $1 D-I ; n=3$ mice for each; Cdh4: $56.4 \pm 8.2 \%, 79 \mathrm{ChCs}$ (the total number of cells counted); Cdh6: $100 \pm$ 0\%, 97 ChCs; Cdh9: $78.7 \pm 2.7 \%$, 89 ChCs]. However, remarkably, all $\mathrm{RFP}^{+}$nc-ChCs expressed Cdh6 and only Cdh6 showed preferential expression in $\mathrm{RFP}^{+}$nc-ChCs compared with other IN types (Figure $1 \mathrm{H} ; n=3$ mice for each; ChC: $100 \pm 0 \%, 97$ cells; PV: $40.6 \pm 3.4 \%, 355$ cells; SOM: $20.6 \pm$ 2.9\%, 246 cells; VIP: $19.7 \pm 1.9 \%, 383$ cells; one-way ANOVA, $p<0.0001)$. These results suggest that $C d h 6$ is a reliable and preferential marker for nc-ChCs that are labeled in Nkx2.1CreER;Ai14/+ mice.

\section{Cdh6-CreER mice provide reliable genetic access to $\mathrm{h}-\mathrm{ChCs}$}

Reliable and preferential expression of $C d h 6$ in nc-ChCs that are labeled in Nkx2.1-CreER;Ai14/+ mice suggests that Cdh6 is a general marker for ChCs throughout the cortex, including the hippocampus. We reasoned that mice targeting the Cdh6 gene locus might provide us with a genetic handle on $\mathrm{h}$-ChCs. To test this idea, we used Cdh6-CreER knock-in mice (kindly provided by Dr. Joshua Sanes, Harvard University). Because the result of CISH showed that $C d h 6$ is also likely expressed in PNs in the CA1 region (Fig. 2A), we took advantage of an intersectional method (Taniguchi et al., 2011; Madisen et al., 2015) to label GABAergic Cdh6-expressing neurons selectively. We used Cdh6-CreER mice, Dlx5/6-Flp mice (which express Flp in all GABAergic interneurons), and Ai65 reporter mice (which drive RFP expression in cells coexpressing Cre and Flp) (Fig. 2B). We induced CreER activity in Cdh6-CreER;Dlx5/6-Flp;Ai65/+ mice by injecting Tmx at P5 and analyzed their brains at P21. As expected, we found that $\sim 40 \%$ of $\mathrm{RFP}^{+}$cells in the hippocampus are ChCs (Fig. $2 C-E, G-I$, Table $3 ; n=3$ mice), which are characterized by axonal arbors confined to the dorsal half of the SP in the CA region and/or close apposition of axonal varicosities to AISs immunostained by anti-AnkG antibodies (Fig. 2G-I, bottom). With high-dose $(6 \mathrm{mg} / 30 \mathrm{~g}$ of body weight $)$ and medium-dose ( $2 \mathrm{mg} / 30 \mathrm{~g}$ of body weight) Tmx, we could label $\sim 50$ and $25 \mathrm{~h}$-ChCs per brain, respectively (Table $3 ; n=3$ mice for each). Administration of high-dose Tmx resulted in RFP labeling of at least some 


\section{A Nkx2.1-CreER;LSL-RFP (E17 Tmx-Induction)}

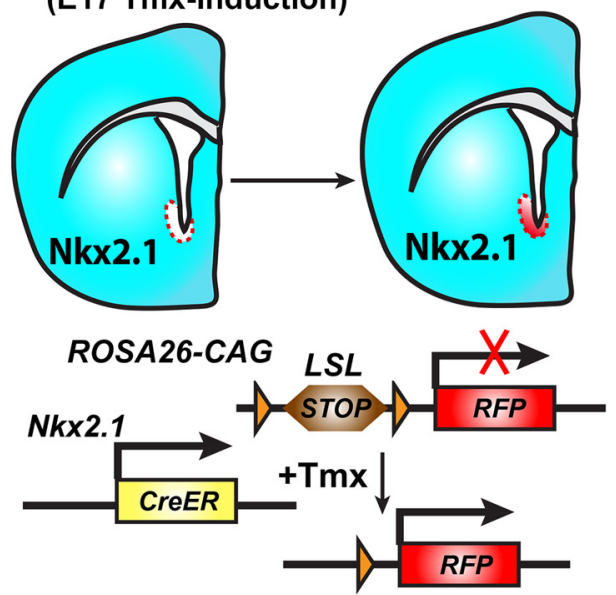

B
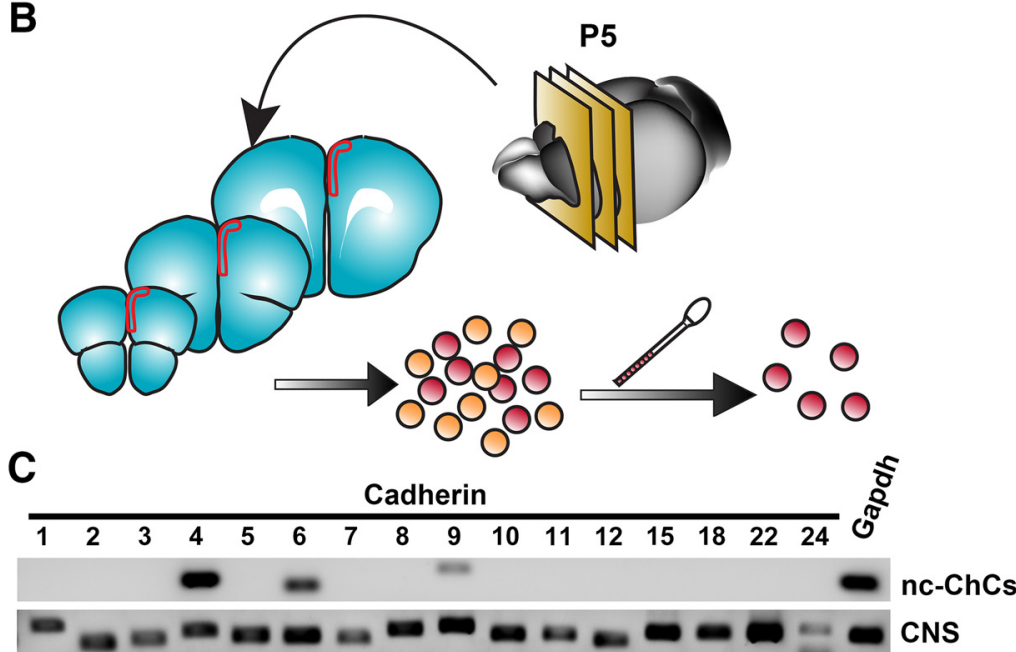
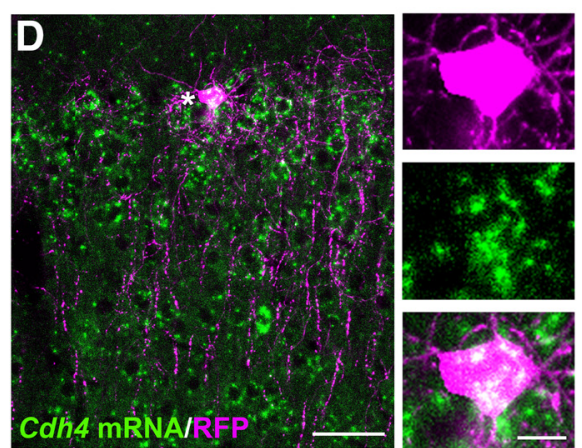

G

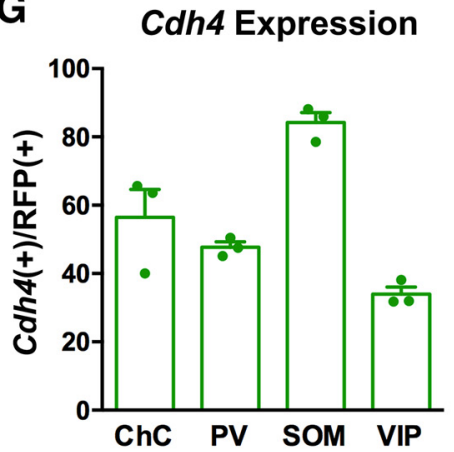

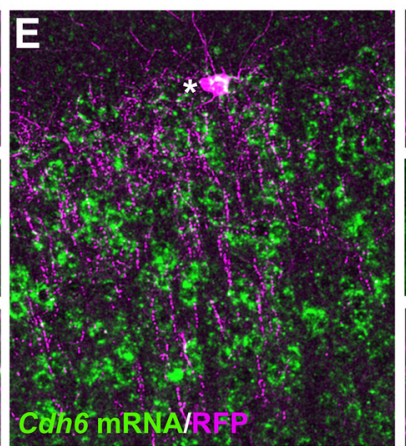

H

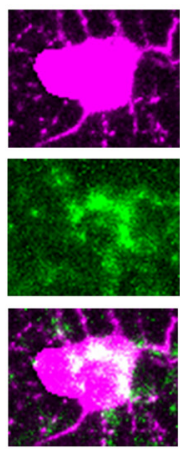

Coh6 Expression

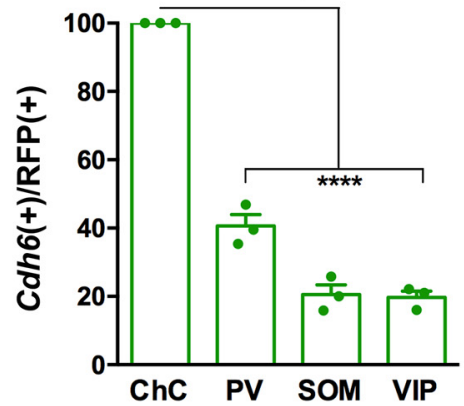

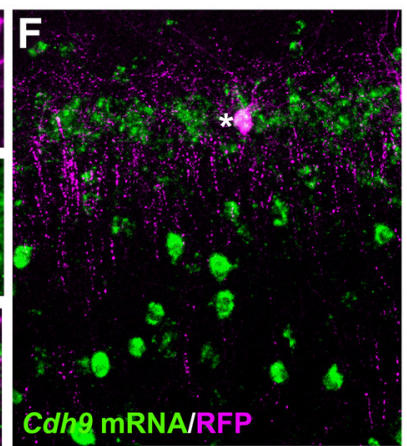

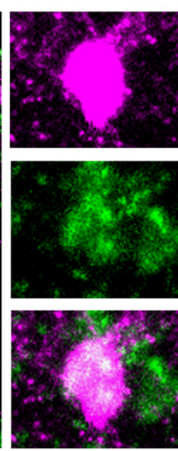

I

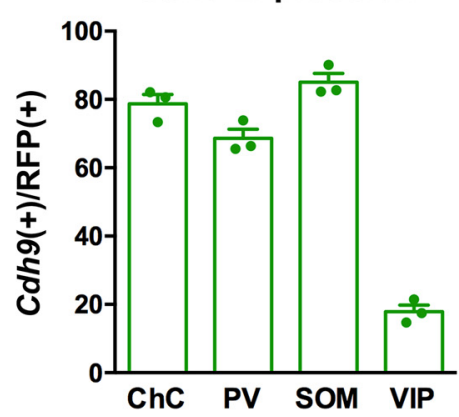

Figure 1. Cdh6 is expressed preferentially in nc-ChCs labeled in Nkx2.1-CreER;Ai14 mice. A, Top schematic of late embryonic coronal brain sections shows RFP induction in the Nkx2.1-expressing MGE of Nkx2.1-CreER;Ai14 mice. Bottom schematic denotes Tmx-induced, CreER-dependnet RFP expression from an Ai14 reporter. B, Schematic showing procedures for single-cell pickups of P5 young nc-ChCs. Fifty RFP ${ }^{+}$cells from the medial prefrontal and cingulate cortices of NkX2.1-CreER;Ai14 mice were collected manually. C, PCR-based screening of classic cadherins. The top shows PCR products amplified from CDNAs of P5 nc-ChCs. The bottom shows PCR products amplified from CDNAs of P10 control tissues including a whole brain and a spinal cord. Each number represents the name of cadherin (e.g., 6 corresponds to (dh6). Note that Cdh4, Cdh6, and (dh9 are detected from nc-ChC CDNAs. D-F, Confocal projection images showing FISH signals for cadherin mRNAs (green) and immunofluorescent signals for RFP (magenta) expressed in L2 nc-ChCs of P21 Nkx2.1-CreER;Ai14 mice. Expression of Cdh4 (D), Cdh6 (E), and Cdh9 (F) mRNAs is shown. Confocal single optical sections in right small panels represent magnified images of the cells marked with asterisks showing RFP, FISH, and FISH/RFP signals from top to bottom. G-I, Quantification of the fraction of cadherin-expressing neocortical cells in distinct IN types including nc-ChCs, PV-INs, SOM-INs, and VIP-INs. Data from FISH of Cdh4 (G), Cdh6 (H), and Cdh9 (I) are shown. Note that only Cdh6 shows preferential expression in nc-ChCs ( $n=3$ mice for each; ChC: $100 \pm 0 \%, 97$ cells; PV: $40.6 \pm 3.4 \%, 355$ cells; S0M: $20.6 \pm 2.9 \%, 246$ cells; VIP: $19.7 \pm 1.9 \%$, 383 cells; one-way ANOVA, $p<0.0001)$. Data are presented as mean \pm SEM. Scale bars: $\boldsymbol{D}-\boldsymbol{F}, 50 \mu \mathrm{m}$; right small panels in $\boldsymbol{D}-\boldsymbol{F}, 10 \mu \mathrm{m}$.

h-ChCs in all major hippocampal subregions, including the CA1 (Fig. 2C,G), the CA3 (Fig. 2D,H), and the dentate gyrus (DG) (Fig. 2E, $I$ ) in every animal (Fig. $2 K$, Table 3 ). When confined to principal cell layers in the CA1, the CA3, and the DG (i.e., the SP of the CA1 and the CA3 and the granule cell layer of the DG), $\sim 80 \%, 50 \%$, and $20 \%$ of $\mathrm{RFP}^{+}$cells, respectively, were ChCs (Figure $2 K$, Table 3; $n=3$ mice; CA1: $78.9 \pm 2.8 \%, 193 \mathrm{RFP}^{+}$ cells; CA3: $46.2 \pm 10.4 \%, 25 \mathrm{RFP}^{+}$cells; DG: $21.3 \pm 5.3 \%, 36$ $\mathrm{RFP}^{+}$cells). A large fraction of $\mathrm{RFP}^{+} \mathrm{h}$-ChCs were found in the CA1 (Fig. $2 L$, Table 4; $n=3$ mice, $179 \mathrm{RFP}^{+}$cells; CA1: $89.2 \pm$
2.5\%; CA3: $6.8 \pm 2.9 \%$; DG: $4.0 \pm 0.8 \%$ ). In the CA region, the majority of $\mathrm{RFP}^{+} \mathrm{h}$-ChCs projected prominent basal dendrites into the stratum oriens (SO) and apical dendrites past the stratum radiatum into the stratum lacunosum moleculare (Fig. $2 G, H)$. Although the majority of $\mathrm{RFP}^{+} \mathrm{h}$-ChCs were located in the SP, a small fraction of $\mathrm{RFP}^{+} \mathrm{h}$-ChCs were found in the SO (Figure $2 M$, Table $5 ; n=3$ mice; $172 \mathrm{ChCs}$; SP ventral half: $27.1 \pm$ 4.0\%; SP dorsal half: $68.2 \pm 4.7 \%$; SO: $4.7 \pm 0.7 \%$ ). We also found preferential localization of $\mathrm{RFP}^{+} \mathrm{h}-\mathrm{ChCs}$ in the dorsal half within the SP (Fig. 2M; one-way ANOVA, $p<0.0001$ ). 


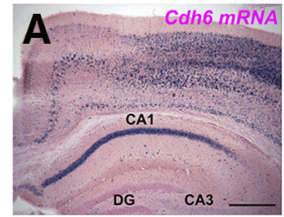

CDaplirfp

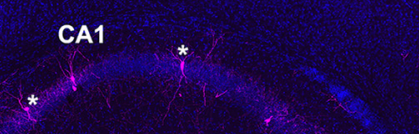

CA3

DG

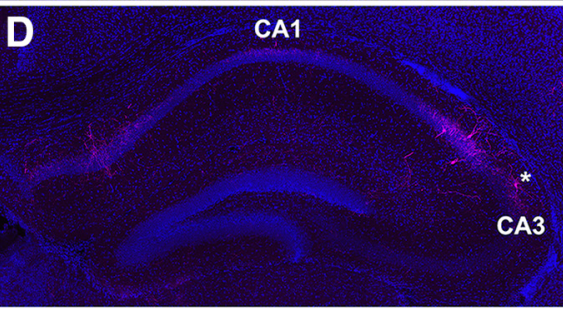

E CA1

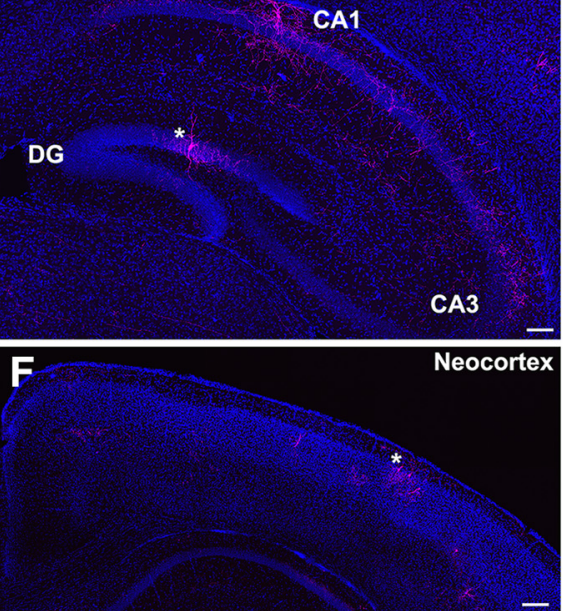

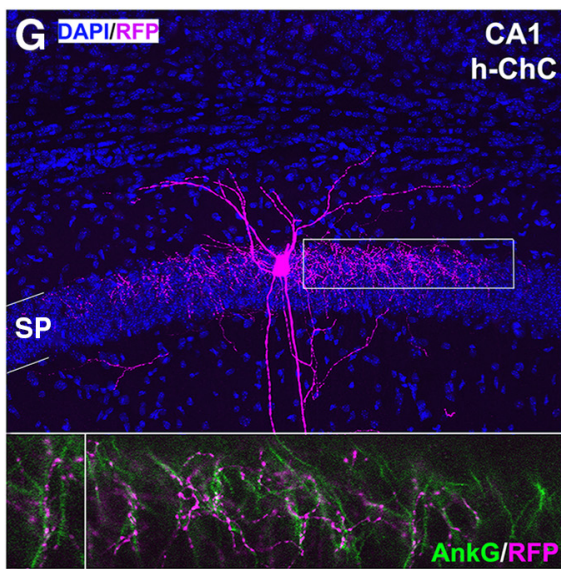
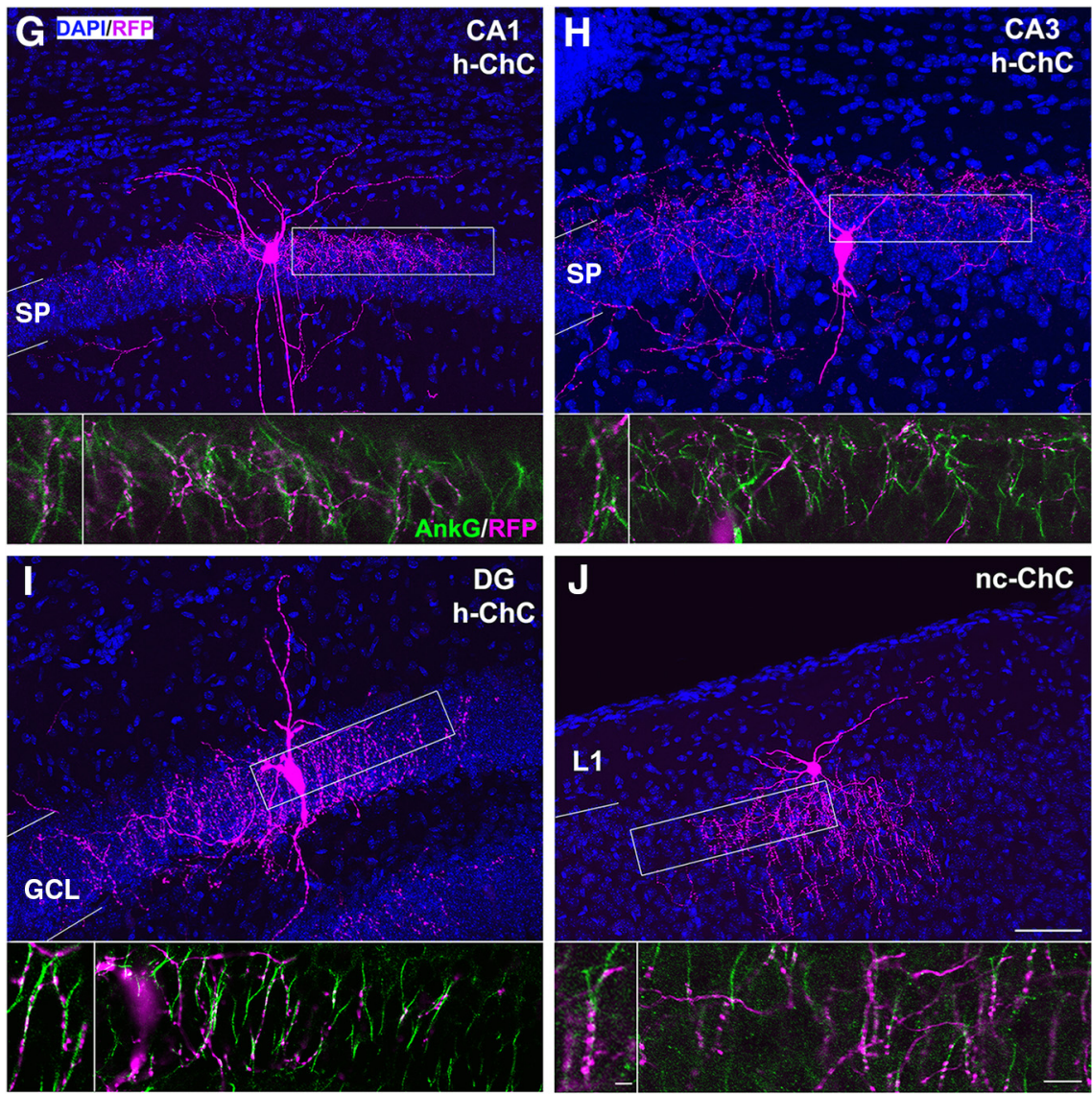

K

L

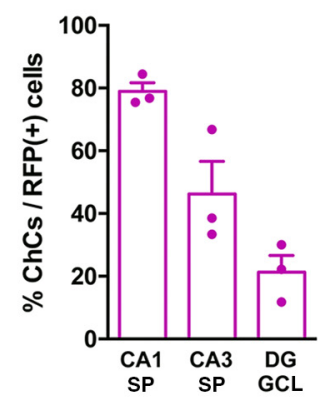

M

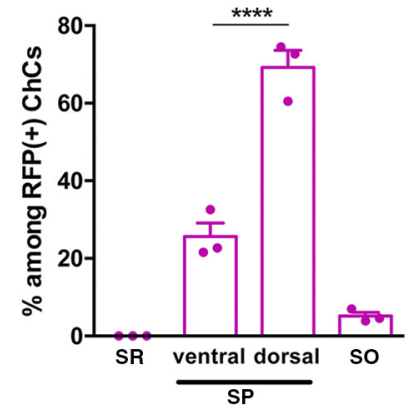

Figure 2. Cdh6-CreER mice provide reliable genetic access to h-ChCs. A, P21 coronal brain section showing Cdh6 CISH signals in the hippocampus. Note that Cdh6 $\mathrm{mRNA}$ is expressed in the CA1 stratum pyramidale (SP) layer. (dh6 mRNA is expressed likely in both PNs and INs. B, Schematic showing an intersectional strategy using Cdh6-CreER, Dlx5/6-Flp, and a dual reporter (Ai65) to label $\mathrm{Cdh6}^{+}$INs. $\mathbf{C}-\boldsymbol{F}$, Confocal projection images showing distribution of RFP ${ }^{+}$cells (magenta) in the hippocampus (C-E) and the neocortex (F) of P21 Cdh6-CreER:Dlx5/6-Flp:Ai65 mice induced with a high dose of Tmx. DAPI staining (blue) shows the cytoarchitecture of the hippocampus and the neocortex. RFP ${ }^{+} \mathrm{h}$-ChCs (asterisks) can be found in all major subregions of the hippocampus, including the $\mathrm{CA1}$ ( $\boldsymbol{C}$, the $\mathrm{CA3}(\boldsymbol{D})$, and the DG (E). RFP ${ }^{+}$INs, which include nc-ChCs (asterisk), are sparsely distributed within the neocortex (F). G-J, High-magnification confocal projection images showing RFP ${ }^{+}$Ch(s in the CA1 (G), the $C A 3(\boldsymbol{H})$, the DG $(\boldsymbol{I})$, and the neocortex $(\boldsymbol{J})$. Confocal single optical sections in bottom right panels represent magnified images of boxed areas at top showing axonal varicosities (magenta) apposed to AlSs immunostained with anti-AnkG antibodies (green). Bottom left panels show individual cartridge structures. Tissues are counterstained with DAPI (blue). GCL, Granule cell layer. $\boldsymbol{K}$, Fraction of h-ChCs among $\mathrm{RFP}^{+}$INs in the principal cell layer of distinct hippocampal subregions ( $n=3$ mice; CA1:78.9 $\pm 2.8 \%, 193 \mathrm{RFP}^{+}$cells; CA3:46.2 $\pm 10.4 \%, 25 \mathrm{RFP}^{+}$cells; DG: $21.3 \pm 5.3 \%, 36 \mathrm{RFP}{ }^{+}$cells). L, Distribution of $\mathrm{RFP}^{+} \mathrm{h}$-ChCs in hippocampal subregions. Among total RFP ${ }^{+} \mathrm{h}$-ChCs, the majority resides in the CA1, with smaller populations in the CA3 and the DG $(n=3$ mice, $179 \mathrm{ChCs} ; \mathrm{CA1}: 89.2 \pm 2.5 \% ; \mathrm{CA3}: 6.8 \pm 2.9 \%$; DG: $4.0 \pm 0.8 \%) \cdot M$, Laminar distribution of RFP ${ }^{+} \mathrm{h}$-ChCs within CA regions of the hippocampus. Although a small but significant population of RFP ${ }^{+} \mathrm{h}$-ChCs reside in the stratum oriens (SO), the majority of $\mathrm{RFP}^{+} \mathrm{h}$-ChCs are found in SP ( $n=3$ mice, $172 \mathrm{ChCs}$; stratum radiatum (SR):0\%; ventral SP: $27.1 \pm 4.0 \%$; dorsal SP: $68.2 \pm 4.7 \% ; S 0: 4.7 \pm 0.7 \%$ ) Data are presented as mean \pm SEM. Scale bars: $A: 500 \mu \mathrm{m}$; $\mathbf{C}-\mathbf{E}: 100 \mu \mathrm{m} ; \boldsymbol{F}, 200 \mu \mathrm{m}$; top of $\mathbf{G}-\boldsymbol{J}, 50 \mu \mathrm{m}$; bottom right panels of $\mathbf{G}-\boldsymbol{J}, 10 \mu \mathrm{m}$; bottom left panels of $\mathbf{G}-\boldsymbol{J}, 2.5 \mu \mathrm{m}$.

In the neocortex, although a small number of ChCs were labeled in sensory areas (Fig. $2 F, J$ ), those in the mPFC and the anterior cingulate cortex, where ChCs are most enriched in the neocortex (Taniguchi et al., 2013), failed to be labeled in Cdh6CreER;Dlx5/6-Flp;Ai65/+ mice. The most likely possibility is that the expression of CreER in Cdh6-CreER mice fails to recapitulate faithfully that of endogenous $C d h 6$. A replacement of a $C d h 6$ coding region with CreER might partially delete essential regulatory elements for the normal expression of a Cdh6 gene.

\section{CR is expressed in a subset of $\mathrm{h}-\mathrm{ChCs}$ but not nc-ChCs}

Although neurochemical markers have been used to classify canonical IN types, no systematic immunohistochemical analyses have been performed on h-ChCs. To characterize the neurochem- 
Table 3. Ratio of $h$-ChCs to total RFP( + ) cells by hippocampal subregion

\begin{tabular}{|c|c|c|c|c|c|c|c|c|c|c|c|c|}
\hline & \multicolumn{3}{|l|}{ Hippocampus } & \multicolumn{3}{|l|}{ CA1 SP } & \multicolumn{3}{|l|}{ CA3 SP } & \multicolumn{3}{|l|}{ DG GCL } \\
\hline & \multirow{2}{*}{$\begin{array}{l}\operatorname{RFP}(+) \\
\text { Cells }\end{array}$} & \multicolumn{2}{|l|}{$\operatorname{RFP}(+)$} & \multirow{2}{*}{$\begin{array}{l}\text { RFP }(+) \\
\text { Cells }\end{array}$} & \multicolumn{2}{|l|}{$\operatorname{RFP}(+)$} & \multirow{2}{*}{$\begin{array}{l}\text { RFP }(+) \\
\text { Cells }\end{array}$} & \multicolumn{2}{|l|}{$\operatorname{RFP}(+)$} & \multirow{2}{*}{$\begin{array}{l}\text { RFP }(+) \\
\text { Cells }\end{array}$} & \multirow{2}{*}{$\begin{array}{l}\operatorname{RFP}(+) \\
\text { ChCs }\end{array}$} & \multirow[b]{2}{*}{$\%$} \\
\hline & & ChCs & $\%$ & & $\mathrm{ChCs}$ & $\%$ & & ChCs & $\%$ & & & \\
\hline $6 \mathrm{mg} / 30 \mathrm{~g} \operatorname{Tmx}$ & $160.7 \pm 26.8$ & $59.7 \pm 6.8$ & $37.7 \pm 1.8 \%$ & $64.3 \pm 9.0$ & $50.7 \pm 6.7$ & $78.9 \pm 2.8 \%$ & $8.3 \pm 2.9$ & $4 \pm 1.5$ & $46.2 \pm 10.4 \%$ & $12 \pm 2.5$ & $2.3 \pm 0.3$ & $21.3 \pm 5.3 \%$ \\
\hline Animal 2 & 214 & 73 & $34.1 \%$ & 82 & 63 & $76.8 \%$ & 13 & 5 & $38.5 \%$ & 17 & 2 & $11.8 \%$ \\
\hline Animal 3 & 138 & 55 & $39.9 \%$ & 58 & 49 & $84.5 \%$ & 3 & 1 & $33.3 \%$ & 10 & 3 & $30.0 \%$ \\
\hline $2 \mathrm{mg} / 30 \mathrm{~g} \operatorname{Tmx}$ & $73.0 \pm 9.9$ & $25.7 \pm 2.9$ & $36.1 \pm 5.1 \%$ & $22.0 \pm 3.5$ & $18.0 \pm 2.6$ & $82.3 \pm 2.9 \%$ & $7.7 \pm 1.3$ & $6.0 \pm 1.0$ & $78.5 \pm 0.7 \%$ & $5.3 \pm 1.8$ & $1.7 \pm 1.2$ & $22.2 \pm 14.7 \%$ \\
\hline Animal 3 & 75 & 21 & $28.0 \%$ & 16 & 14 & $87.5 \%$ & 9 & 7 & $77.8 \%$ & 2 & 0 & $0.0 \%$ \\
\hline
\end{tabular}

Table 4. Distribution of $h$-ChCs by hippocampal subregion

\begin{tabular}{|c|c|c|c|c|c|c|c|}
\hline & \multirow{2}{*}{$\begin{array}{l}\text { Hippocampus } \\
\mathrm{RFP}(+) \mathrm{ChCs}\end{array}$} & \multicolumn{2}{|l|}{ CA1 } & \multicolumn{2}{|l|}{ CA3 } & \multicolumn{2}{|l|}{$\mathrm{DG}$} \\
\hline & & $\mathrm{ChCs}$ & $\%$ & $\mathrm{ChCs}$ & $\%$ & $\mathrm{ChCs}$ & $\%$ \\
\hline $6 \mathrm{mg} / 30 \mathrm{~g} \operatorname{Tm} \mathrm{x}$ & $59.7 \pm 6.8$ & $53.3 \pm 6.7$ & $89.2 \pm 2.5 \%$ & $4.0 \pm 1.5$ & $6.8 \pm 2.9 \%$ & $2.3 \pm 0.3$ & $4.0 \pm 0.8 \%$ \\
\hline Animal 1 & 51 & $75.5 \%$ & 9 & 6 & $66.7 \%$ & 9 & 2 \\
\hline Animal 2 & 73 & $76.8 \%$ & 13 & 5 & $38.5 \%$ & 17 & 2 \\
\hline Animal 3 & 55 & $84.5 \%$ & 3 & 1 & $33.3 \%$ & 10 & 3 \\
\hline $2 \mathrm{mg} / 30 \mathrm{~g} \operatorname{Tmx}$ & $25.7 \pm 2.9$ & $18.0 \pm 2.6$ & $69.6 \pm 2.3 \%$ & $6.0 \pm 1.0$ & $24.0 \pm 5.0 \%$ & $1.7 \pm 1.2$ & $6.4 \pm 4.9 \%$ \\
\hline Animal 1 & 31 & 23 & $74.2 \%$ & 7 & $22.6 \%$ & 1 & $3.2 \%$ \\
\hline Animal 2 & 25 & 17 & $68.0 \%$ & 4 & $16.0 \%$ & 4 & $16.0 \%$ \\
\hline Animal 3 & 21 & 14 & $66.7 \%$ & 7 & $33.3 \%$ & 0 & $0 \%$ \\
\hline
\end{tabular}

Table 5. Laminar distribution of h-ChCs in CA

\begin{tabular}{|c|c|c|c|c|c|c|c|c|c|}
\hline & \multirow{2}{*}{$\begin{array}{l}\text { CA } \\
\text { RFP(+) ChCs }\end{array}$} & \multicolumn{2}{|l|}{ SR } & \multicolumn{2}{|l|}{ SP (ventral) } & \multicolumn{2}{|l|}{ SP (dorsal) } & \multicolumn{2}{|l|}{ SO } \\
\hline & & $\mathrm{RFP}(+) \mathrm{ChCs}$ & $\%$ & $\operatorname{RFP}(+) \mathrm{ChCs}$ & $\%$ & $\mathrm{RFP}(+) \mathrm{ChCs}$ & $\%$ & $\mathrm{RFP}(+) \mathrm{ChCs}$ & $\%$ \\
\hline $6 \mathrm{mg} / 30 \mathrm{~g} \operatorname{Tmx}$ & $57.3 \pm 6.9$ & & & $15.3 \pm 2.2$ & $27.1 \pm 4.0 \%$ & $39.3 \pm 6.1$ & $68.2 \pm 4.7 \%$ & $2.7 \pm 0.3$ & $4.7 \pm 0.7 \%$ \\
\hline Animal 3 & 52 & 0 & $0 \%$ & 11 & $21.2 \%$ & 39 & $75.0 \%$ & 2 & $3.8 \%$ \\
\hline $2 \mathrm{mg} / 30 \mathrm{~g} \operatorname{Tmx}$ & $26.0 \pm 2.9$ & & & $12.0 \pm 1.7$ & $45.8 \pm 1.6 \%$ & $9.7 \pm 0.7$ & $37.7 \pm 2.6 \%$ & $4.3 \pm 0.7$ & $16.5 \pm 1.4 \%$ \\
\hline Animal 1 & 26 & 0 & $0 \%$ & 12 & $46.2 \%$ & 9 & $34.6 \%$ & 5 & $19.2 \%$ \\
\hline
\end{tabular}

SR, Stratum radiatum.

ical properties of h-ChCs, we first sought to identify neurochemical markers that are expressed by hippocampal RFP ${ }^{+}$cells in Cdh6CreER;Dlx5/6-Flp;Ai65/+ mice and then investigated whether they are expressed by h-ChCs. We tested representative neurochemical markers for canonical IN types including PV, CR, nNOS, SOM, and VIP. IHC was performed on brain sections from Cdh6-CreER;Dlx5/ 6-Flp;Ai65/+ mice with medium Tmx induction.

Consistent with our FISH data showing that only a minor fraction of SOM-INs and VIP-INs in the hippocampus express the Cdh6 gene (data not shown: $n=3$ mice for each; SOM: $3.8 \%$, 155 cells; VIP: $0 \%, 103$ cells), no SOM and VIP expression was observed in hippocampal RFP ${ }^{+}$cells [Figure $3 A ; n=3$ mice for each; SOM: 0\% (112 ChCs), 0\% (104 non-ChCs); VIP: 0\% (66 ChCs), $0 \%$ (77 non-ChCs)]. We found that hippocampal $\mathrm{RFP}^{+}$ cells express PV, CR, and n-NOS (Fig. 3A). nNOS expression was found only in non-ChCs (Fig. $3 A, B$ ). Approximately one-third of hippocampal $\mathrm{RFP}^{+}$non-ChCs expressed n-NOS [Figure $3 A$; $n=3$ mice; $0 \%$ (92 ChCs), $27.0 \pm 2.1 \%$ (121 non-ChCs)]. Conversely, $\mathrm{PV}$ and $\mathrm{CR}$ expression was substantially confined to h-ChCs among hippocampal $\mathrm{RFP}^{+}$cells [Fig. 3 A, C,E; $n=3$ mice for each; PV: $65.8 \pm 0.5 \%$ (123 ChCs), $4.7 \pm 1.0 \%$ (231 non-ChCs); CR: $19.8 \pm 0.9 \%$ (106 ChCs), 0\% (139 non-ChCs)].

As expected from previous studies showing PV expression in h-ChCs (Viney et al., 2013; Takács et al., 2015), approximately two-thirds of $\mathrm{RFP}^{+}$h-ChCs were immunopositive for PV (Fig. $3 A, C, D$; for quantitation, see above) in Cdh6-CreER;Dlx5/6-Flp; Ai65/+ mice. $\mathrm{RFP}^{+}$nc-ChCs in Cdh6-CreER;Dlx5/6-Flp/Ai65 mice also showed a similar rate of PV expression (Fig. $3 C, D$ : $n=3$ mice; $54.9 \pm 4.3 \%, 66$ nc-ChCs).

To our surprise, we found that almost $20 \%$ of RFP ${ }^{+}$h-ChCs express CR, which has never been observed in ChCs (Fig. $3 \mathrm{~A}, \mathrm{E}$; for the quantitation, see above). $\mathrm{CR}^{+} / \mathrm{RFP}^{+} \mathrm{h}$-ChCs were found in the CA1 and the CA3 but not the DG with a slight but not statistically significant bias in distribution within the SP $(n=3$ mice; $20 \mathrm{CR}^{+} / \mathrm{RFP}^{+} \mathrm{h}-\mathrm{ChCs}$; SP ventral half: $31.2 \pm 12.1 \%$; SP dorsal half: $61.0 \pm 11.5 \%$; SO: $7.9 \pm 5.1 \%$ ). We also examined CR expression in $\mathrm{RFP}^{+}$nc-ChCs labeled in Cdh6-CreER;Dlx5/6-Flp; Ai65/+ and Nkx2.1-CreER;Ai14 mice and confirmed that RFP ${ }^{+}$ nc-ChCs never express CR (Fig. $3 E, F$ and data not shown; $n=3$ mice for each; Cdh6-CreER;Dlx5/6-Flp;Ai65/+: 0\%, 32 nc-ChCs; Nkx2.1-CreER;Ai14: 0\%, 56 nc-ChCs). To further corroborate this finding, we performed FISH for CR mRNA in Cdh6-CreER; Dlx5/6-Flp;Ai65/+ mice. Expression of CR mRNAs in $\mathrm{RFP}^{+}$ h-ChCs was consistent with IHC results (Fig. $3 G: n=4$ mice; $15.8 \pm 4.0 \%, 81$ h-ChCs).

To further characterize the neurochemical identity of $\mathrm{CR}^{+} /$ $\mathrm{RFP}^{+} \mathrm{h}$-ChCs, we investigated whether they express PV. To this end, we performed double immunostaining using the previously 
A
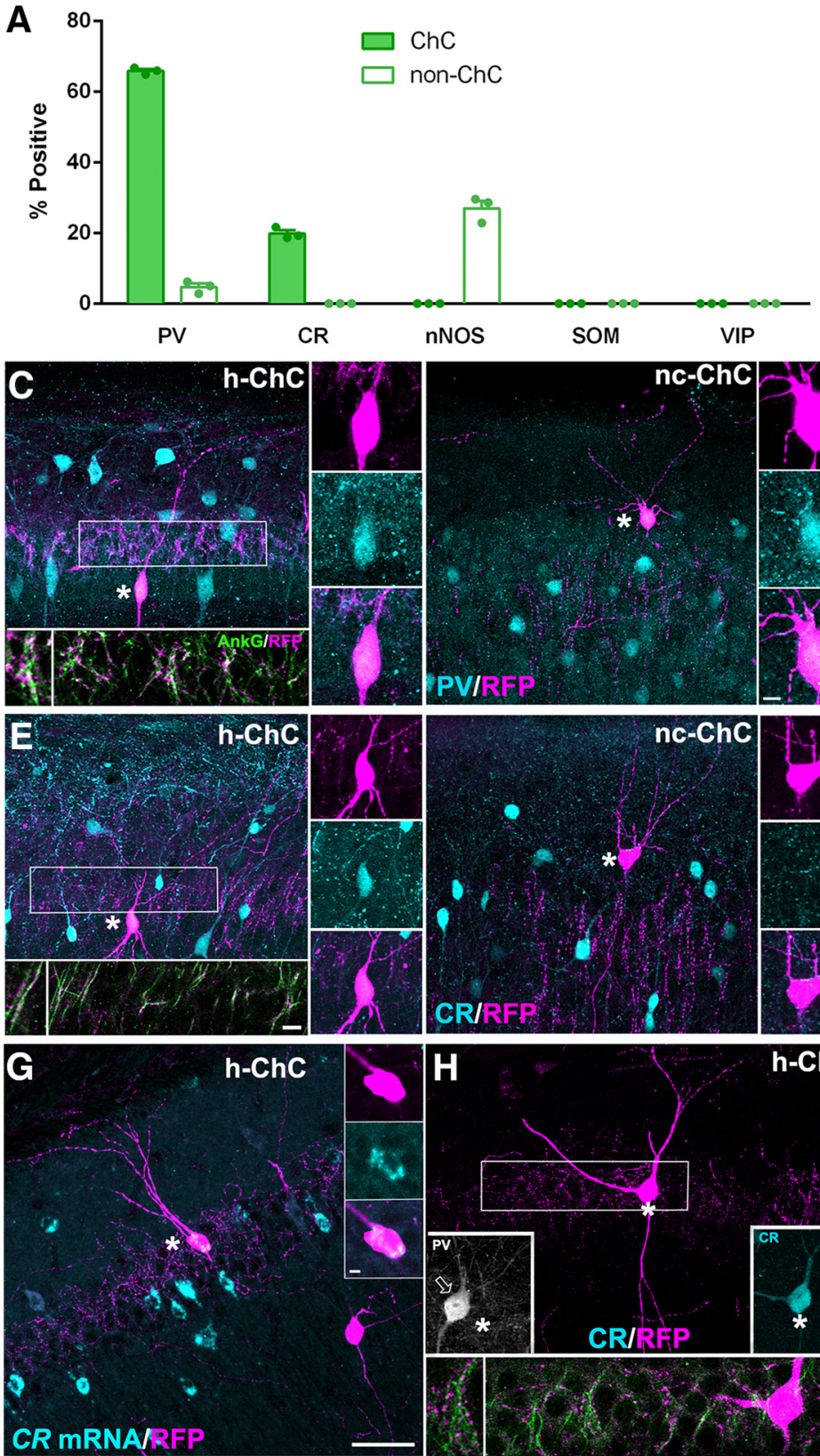
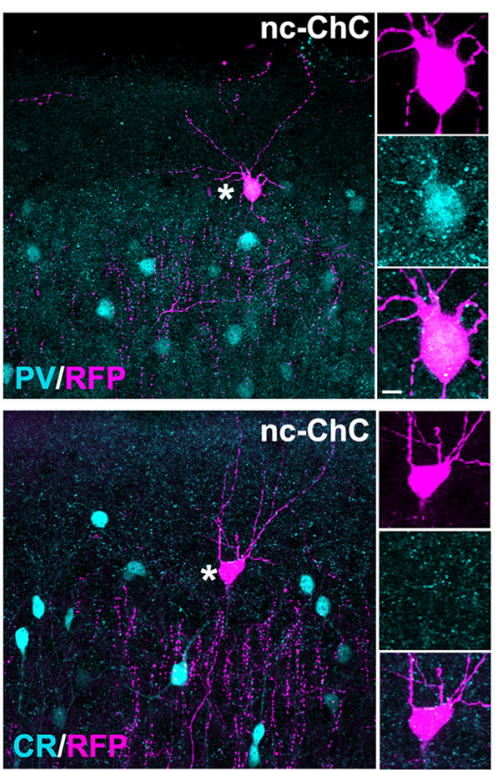

$\mathbf{H}$

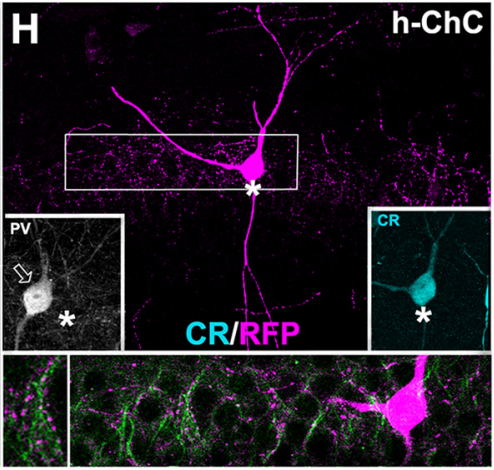

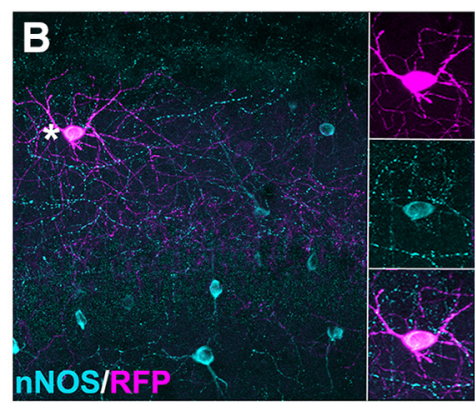
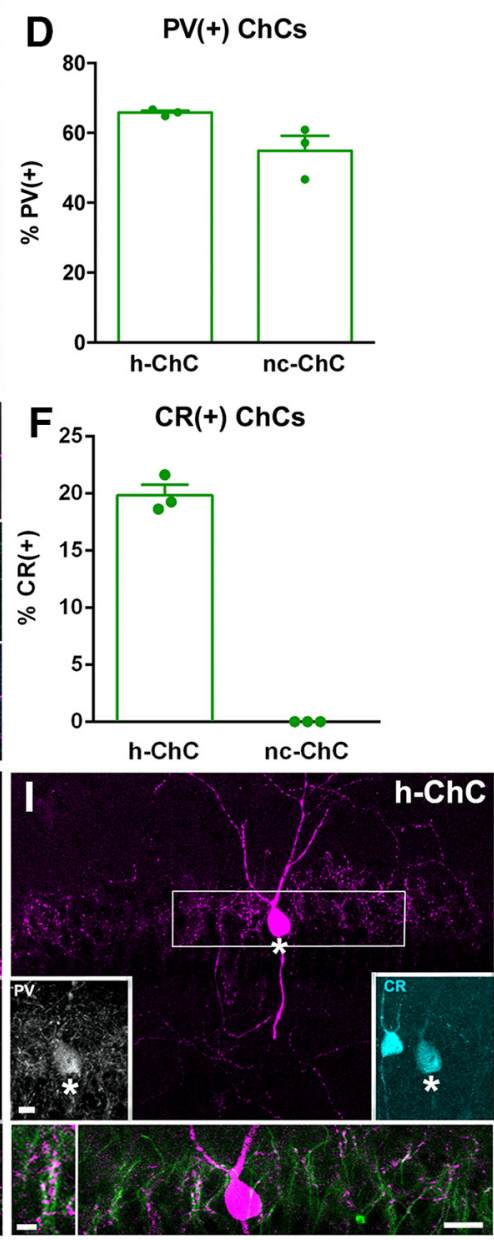

Figure 3. h-ChCs but not nc-ChCs contain a CR-expressing subpopulation in Cdh6-CreER;D/x5/6-Flp;Ai65/+ mice. A, Immunohistochemical characterization of RFP + INs in the hippocampus of P21 Cdh6-CreER;Dlx5/6-Flp;Ai65/+ mice. RFP ${ }^{+}$cells are divided into ChCs and non-ChCs. Note that RFP ${ }^{+}$h-ChCs contain PV-expressing and CR-expressing populations, whereas non-ChCs include nNOS-expressing and PV-expressing populations. [ $n=3$ mice for each; PV: $65.8 \pm 0.5 \%$ (123 ChCs), $4.7 \pm 1.0 \%$ (231 non-ChCs); CR: $19.8 \pm 0.9 \%$ (106 ChCs), $0 \%$ (139 non-ChCs); nN0S: $0 \%$ (92 ChCs), $27.0 \pm 2.1 \%$ (121 non-ChCs); S0M: 0\% (112 ChCs), 0\% (231 non-ChCs); VIP: 0\% (66 ChCs), 0\% (77 non-ChCs)]. B, Confocal projection image showing an RFP + non-ChC (magenta) with nNOS expression (cyan) in the hippocampus. Asterisk indicates an nNOS ${ }^{+} / \mathrm{RFP}^{+}$non-ChC.Confocal single optical sections in right small panels represent RFP, nNOS, and nNOS/RFP signals from top to bottom in the nNOS ${ }^{+} / \mathrm{RFP}^{+}$non-ChC. C, Confocal projection images showing PV ${ }^{+} / \mathrm{RFP}^{+}$ChCs in the hippocampus and the neocortex. RFP and PV are shown in magenta and cyan, respectively. Asterisks indicate PV ${ }^{+} / \mathrm{RFP}^{+} \mathrm{ChCs}$. Confocal single optical sections in right small panels represent RFP, PV, and PV/RFP signals from top to bottom in PV ${ }^{+} / \mathrm{RFP}{ }^{+}$ChCs. A confocal single optical section of h-ChC axonal varicosities (magenta) apposed to AlSs immunostained with anti-AnkG antibodies (green) is shown in the left bottom right panel. Left bottom left panel shows individual cartridge structures. D, Quantification of the percentage of PV ${ }^{+} / \mathrm{RFP}^{+} \mathrm{ChCs}$ among RFP ${ }^{+} \mathrm{ChCs}$ in the hippocampus and the neocortex. $n=3$ mice for each; $\mathrm{h}$-ChCs, $65.8 \pm 0.5 \%, 123$ cells; nc-ChCs, $54.9 \pm 4.3 \%, 66$ cells. $\boldsymbol{E}$, Confocal projection images showing CR ${ }^{+} / \mathrm{RFP}^{+} \mathrm{h}-\mathrm{ChCs}$ and $\mathrm{CR}^{-} / \mathrm{RFP}^{+} \mathrm{nc}-\mathrm{ChCs}$. RFP and CR are shown in magenta and cyan, respectively. Asterisks indicate a $\mathrm{CR}^{+} / \mathrm{RFP}^{+} \mathrm{h}$-ChCs and a $\mathrm{CR}^{-} / \mathrm{RFP}^{+} \mathrm{nc}^{-C h C}$. Confocal single optical sections in right small panels represent RFP, CR, and RFP/CR from top to bottom in a CR ${ }^{+} / \mathrm{RFP}{ }^{+} \mathrm{h}_{-}-\mathrm{ChCs}$ and a $\mathrm{CR}^{-} / \mathrm{RFP}^{+}{ }^{+} \mathrm{nc}-\mathrm{ChC}$. A confocal single optical section of h-ChC axonal varicosities (magenta) apposed to AlSs immunostained with anti-AnkG antibodies (green) is shown in the left bottom right panel. Left bottom left panel shows individual cartridge structures. $F$, Quantification of the percentage of $\mathrm{CR}^{+} / \mathrm{RFP}^{+} \mathrm{ChCs}$ among RFP ${ }^{+} \mathrm{ChCs}$ in the hippocampus and the neocortex. $n=3$ mice for each; h-ChCs, $19.1 \pm 0.9 \%, 106$ cells; nc-ChCs, 0\%, 32 cells. G, Confocal projection image showing $C R$ mRNA ${ }^{+} / R_{F P}{ }^{+} h-C h C$. CR mRNA and RFP signals are shown in cyan and magenta, respectively. Asterisk indicates a $C R \mathrm{mRNA}^{+} / \mathrm{RFP}^{+} \mathrm{ChC}$. Confocal single optical sections in insets represent RFP, $C R$ mRNA, and $C R \mathrm{mRNA} / \mathrm{RFP}$ from top to bottom in a $C R$ mRNA ${ }^{+} / \mathrm{RFP}{ }^{+} \mathrm{ChC}$. $\boldsymbol{H}, \boldsymbol{I}$, Top, Confocal projection images of RFP ${ }^{+} \mathrm{h}$-ChCs (magenta). Left insets show PV signals (white). Right insets indicate CR signals (cyan) in RFP ${ }^{+} \mathrm{h}$-ChCs (asterisks). Empty arrow in left inset of Hindicates neighboring $\mathrm{PV}^{+}$cell adjacent to $\mathrm{RFP}^{+} / \mathrm{PV}^{-} \mathrm{h}$-ChC. Confocal single optical sections in bottom right panels represent enlarged images of boxed areas at top showing axonal varicosities

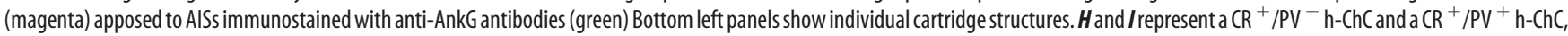
respectively. Data are presented as mean \pm SEM. Scale bars, $50 \mu \mathrm{m}$ [left panels in $\boldsymbol{B}, \boldsymbol{C}$ (nc-ChC), $\boldsymbol{E}$ (nc-ChC); left-top in $\boldsymbol{C}$ (h-ChC), $\boldsymbol{E}$ (h-ChC); $\boldsymbol{G}$; top in $\boldsymbol{H}, \boldsymbol{I}], 10 \mu \mathrm{m}[$ left-lower right panels in $\boldsymbol{C}$ (h-ChC), $\boldsymbol{E}$ (h-ChC); lower right panels in $\boldsymbol{H}, \boldsymbol{I}$; left and right insets in $\boldsymbol{H}, \boldsymbol{I}], 5 \mu \mathrm{m}$ (right small panels in $\boldsymbol{B}, \boldsymbol{C}, \boldsymbol{E}$; insets in $\boldsymbol{G}$ ), and $2.5 \mu \mathrm{m}$ (left-lower left panels in $\boldsymbol{C}(\mathrm{h}$-ChC), $\boldsymbol{E}$ (h-ChC); lower left panels in $\boldsymbol{H}, \boldsymbol{I})$. 

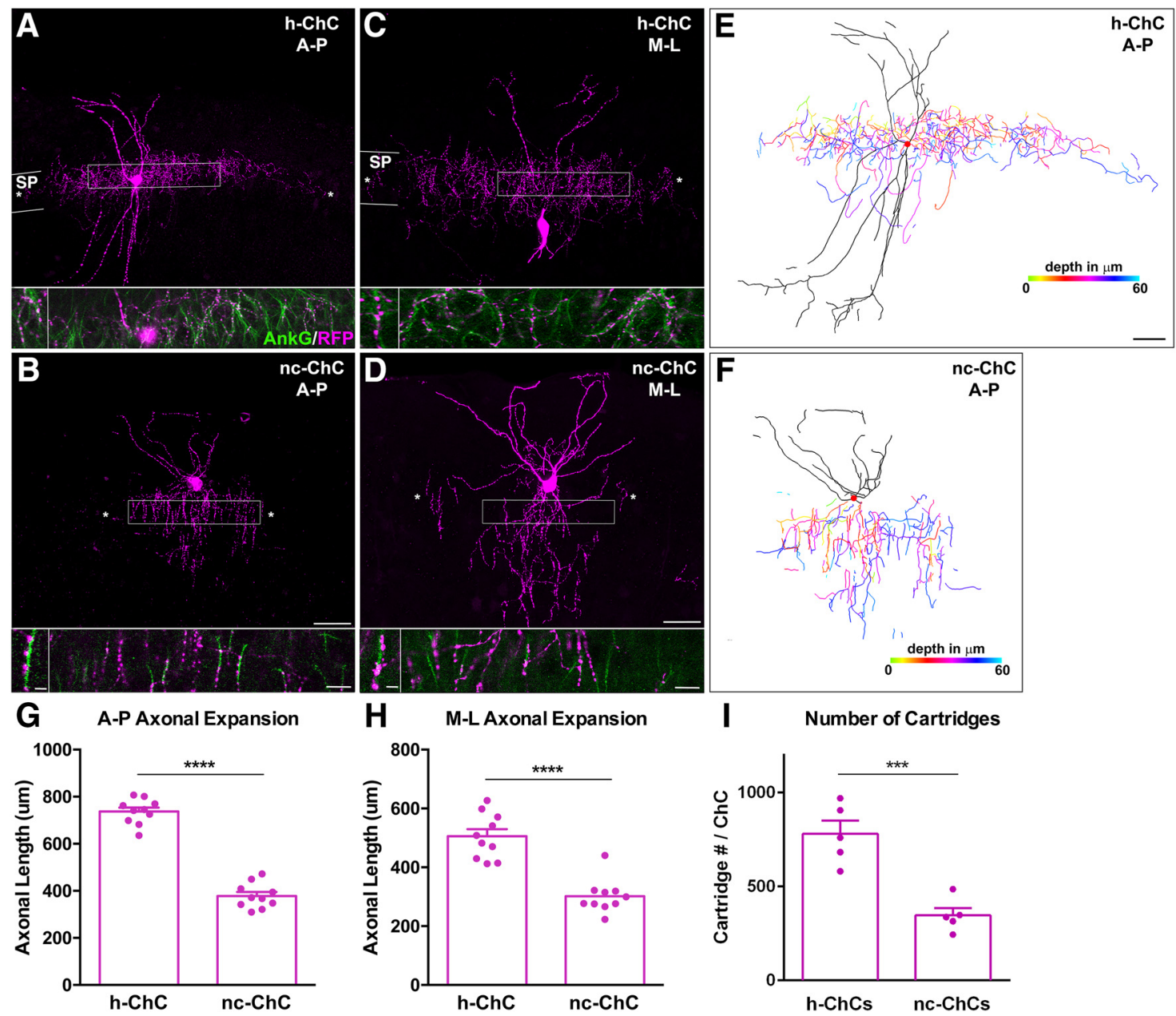

Figure 4. $h$-ChCs innervate much wider area and a greater number of PNs than nc-ChCs in P21 Cdh6-CreER;Dlx5/6-Flp;Ai65/+ mice. $\boldsymbol{A}-\boldsymbol{D}$, Top, Confocal projection images indicating the extent of axonal arbors in RFP ${ }^{+} \mathrm{h}-\mathrm{ChCs}(\boldsymbol{A}, \boldsymbol{C})$ and RFP ${ }^{+} \mathrm{nc}-\mathrm{ChCs}(\boldsymbol{B}, \boldsymbol{D})$. The $\mathrm{A}-\mathrm{P}(\boldsymbol{A}, \boldsymbol{B})$ and $\mathrm{M}-\mathrm{L}(\boldsymbol{C}, \boldsymbol{D})$ extent of ChC axonal arbors in sagittal and coronal sections, respectively, are shown. Asterisks indicate both ends of axonal arbors. Confocal single optical sections in bottom right panels represent enlarged images of boxed areas at top showing axonal varicosities (magenta) aligned along AISs (green) stained with anti-AnkG antibodies. Lower left panels show individual cartridge structures. $\boldsymbol{E}, \boldsymbol{F}, 3 \mathrm{D}$ reconstructions of an $\mathrm{h}-\mathrm{ChC}(\boldsymbol{E})$ and an nc-ChC $(\boldsymbol{F})$ in sagittal sections. Axonal processes are color coded according to their depth. $\mathbf{G}, \boldsymbol{H}$, Quantification of the A-P $(\boldsymbol{G})$ and $\mathrm{M}-\mathrm{L}(\boldsymbol{H})$ extent of axonal arbors in $\mathrm{h}$-ChCs and nc-ChCs. The A-P extent: $n=10$ cells for each; $\mathrm{h}$-ChCs, $736.0 \pm 16.9 \mu \mathrm{m}$; $\mathrm{nc}-\mathrm{ChCs}, 378.3 \pm 16.8 \mu \mathrm{m}$; two-tailed Student's t test, $p<0.0001$. The M-L extent: $n=10$ cells for each; h-ChCs, 505.5 $\pm 24.4 \mu \mathrm{m} ; \mathrm{nc}-\mathrm{ChCs}, 301.4 \pm 18.1 \mu \mathrm{m} ;$ two-tailed Student's $t$ test, $p<$ 0.0001. I, Quantification of the number of AISs innervated by a single ChC. $n=5$ cells for each; $h$-ChCs, $780.5 \pm 71.2 \mathrm{AlSs} ; \mathrm{nc}$-ChCs, $346.4 \pm 39.3$ AlSs; two-tailed Student's t test, $p=0.0007$. Data are presented as mean \pm SEM. Scale bars, $100 \mu \mathrm{m}$ (top in $\boldsymbol{A}, \boldsymbol{B}$ ), $50 \mu \mathrm{m}$ (top in $\boldsymbol{C}, \boldsymbol{D} ;$ and $\boldsymbol{E}, \boldsymbol{F}$ ), $10 \mu \mathrm{m}$ (bottom right panels in $\boldsymbol{A}, \boldsymbol{B}$ ), and $5 \mu \mathrm{m}$ (bottom right panels in $\boldsymbol{C}, \boldsymbol{D}$ ), $2.5 \mu \mathrm{m}$ (bottom left panels in $\boldsymbol{A}-\boldsymbol{D})$.

used rabbit anti-CR antibodies and guinea pig anti-PV antibodies. The staining efficiency of guinea pig anti-PV antibodies was indistinguishable from that of the previously used rabbit anti-PV (rabbit anti-PV: $65.8 \pm 0.5 \%, 123$ ChCs; guinea pig anti-PV: $64.3 \pm 5.4 \%, 106 \mathrm{ChCs}, n=3$ mice each). Approximately half of $\mathrm{CR}^{+} \mathrm{h}-\mathrm{ChCs}$ expressed PV, suggesting that they are classified into at least two subpopulations, $\mathrm{CR}^{+} / \mathrm{PV}^{-} \mathrm{h}-\mathrm{ChCs}$ and $\mathrm{CR}^{+} /$ $\mathrm{PV}^{+}$h-ChCs (Fig. $3 \mathrm{H}, \mathrm{I}: n=3$ mice; $\mathrm{CR}^{+} / \mathrm{PV}^{-}$h-ChCs: $10.4 \pm$ $1.2 \%$; $\mathrm{CR}^{+} / \mathrm{PV}^{+}$h-ChCs: $9.4 \pm 2.1 \%, 106 \mathrm{~h}$-ChCs).

Together, our results identified a novel CR-expressing subpopulation in h-ChCs. The fact that this population appears unique to the hippocampus suggests differential mechanisms for specification/differentiation of h-ChCs and nc-ChCs.

\section{h-ChCs labeled in Cdh6-CreER;Dlx5/6-Flp;Ai65/+ mice} exhibit larger axonal arbors and innervate more PNs than typical nc-ChCs

Distinct IN types display unique axonal/synaptic organization that is one of the key determinants of their output properties
(Jiang et al., 2015). To determine axonal/synaptic organization of h-ChCs accurately without the confusion of overlapping axonal arbors from other INs, we labeled spatially isolated single h-ChCs by inducing RFP in P5 Cdh6-CreER;Dlx5/6-Flp;Ai65/+ pups with a low dose of $\operatorname{Tmx}(0.5 \mathrm{mg} / 30 \mathrm{~g}$ of body weight).

We immediately noticed that $\mathrm{h}-\mathrm{ChC}$ axons span a large A-P distance (Fig. 4A,E). The A-P axonal distance of h-ChCs was 2 -fold larger than that of nc-ChCs (Fig. $4 A, B, E-G ; n=3$ mice; h-ChC: $736.0 \pm 16.9 \mu \mathrm{m}, 10$ cells; nc-ChC: $378.3 \pm 16.8 \mu \mathrm{m}, 10$ cells; two-tailed Student's $t$ test, $p<0.0001$ ). Their axonal expansion along the $\mathrm{M}-\mathrm{L}$ axis was also larger than that of nc-ChCs (Fig. $4 C, D, H ; n=3$ mice; h-ChC: $505.5 \pm 24.4 \mu \mathrm{m}, 10$ cells; nc-ChC: $301.4 \pm 18.1 \mu \mathrm{m}, 10$ cells; two-tailed Student's $t$ test, $p<0.0001$ ).

To understand putative synaptic organization of ChCs, we then investigated how many AISs of PNs are innervated by a single $\mathrm{ChC}$ in the hippocampus and the neocortex. This number is equivalent to the number of cartridges per $\mathrm{ChC}$. In contrast to AISs of nc-PNs, those of hippocampal PNs are extremely difficult to separate because of their high density and multiple orienta- 


\begin{tabular}{|c|c|c|c|}
\hline & $\begin{array}{l}\text { Total no. of } \\
\text { boutons }\end{array}$ & $\begin{array}{l}\text { Boutons per AIS } \\
\text { ( } n=5 \text { AlSs each) }\end{array}$ & No. of AlSs \\
\hline \multicolumn{4}{|l|}{$\mathrm{nc}-\mathrm{ChCs}$} \\
\hline Average & & & $346.4 \pm 39.3$ \\
\hline Cell 1 & 1008 & $3.2 \pm 0.4$ & 315.0 \\
\hline Cell 2 & 783 & $3.2 \pm 0.4$ & 244.7 \\
\hline Cell 3 & 1149 & $3.4 \pm 0.5$ & 337.9 \\
\hline Cell 4 & 1045 & $3.0 \pm 0.5$ & 348.3 \\
\hline Cell 5 & 1361 & $2.8 \pm 0.4$ & 486.1 \\
\hline \multicolumn{4}{|l|}{$\mathrm{h}-\mathrm{ChCs}$} \\
\hline Average & & & $780.5 \pm 71.2$ \\
\hline Cell 1 & 3107 & $3.0 \pm 0.3$ & 970.9 \\
\hline Cell 2 & 2051 & $3.2 \pm 0.2$ & 683.7 \\
\hline Cell 3 & 2719 & $3.0 \pm 0.4$ & 906.3 \\
\hline Cell 4 & 1745 & $3.0 \pm 0.6$ & 581.7 \\
\hline Cell 5 & 2280 & $3.0 \pm 0.4$ & 760.0 \\
\hline
\end{tabular}

tions. Therefore, it was difficult to obtain directly the total number of AISs innervated by a single h-ChC. To overcome this problem, we estimated this number indirectly: we first calculated the average number of varicosities per AIS using fully isolated AISs and then divided the total number of varicosities that are apposed to AISs by the number of varicosities per AIS. We found that the estimated number of AISs innervated by a single h-ChC was significantly higher than those innervated by a single ncChC (Fig. 4I, Table 6; $n=5$ cells for each; h-ChC: $780.5 \pm 71.2$ AISs; nc-ChC: $346.4 \pm 39.3$ AISs; two-tailed Student's $t$ test, $p=0.0007)$. The average length of AISs in the hippocampus was longer than those in the neocortex (hippocampus: $28.6 \pm$ $0.7 \mu \mathrm{m}$; neocortex: $20.0 \pm 0.5 \mu \mathrm{m} ; n=25$ AISs for each from 5 animals).

These results suggest that, despite sharing subcellular synaptic targets, the spatial distribution of axons and the number of PNs innervated by a single $\mathrm{ChC}$ is regulated differentially in the hippocampus and the neocortex.

\section{Early production of h-ChCs labeled in Cdh6-CreER;Dlx5/6- Flp;Ai65/+ mice}

Our findings on distinct terminal phenotypes of h-ChCs and nc-ChCs raised a question as to what could make regional IN variants in the hippocampus and the neocortex different. One plausible explanation is their differential specification due to distinct embryonic origins. Cortical INs arise from the MGE, the caudal ganglionic eminence (CGE), and the preoptic area, each of which produces distinct canonical IN types (Wonders and Anderson, 2006; Batista-Brito and Fishell, 2009; Gelman and Marín, 2010). In addition, studies of genetic fate mapping and BrdU labeling revealed that birth timing is an important factor in the control of IN identity (Miyoshi et al., 2007; Miyoshi et al., 2010; Tricoire et al., 2011; Taniguchi et al., 2013; Donato et al., 2015). Because ChCs likely share the MGE as their spatial origin (Tricoire et al., 2011; Taniguchi et al., 2013), we hypothesized that h-ChCs and nc-ChCs might have distinct temporal origins. To test this hypothesis, we performed BrdU-based birth dating of h-ChCs labeled in Cdh6-CreER;Dlx5/6-Flp;Ai65/+ mice. We injected a single pulse of BrdU into pregnant animals at distinct days between E10 and E16 to label mitotic progenitors (Fig. $5 A$ ). We found that h-ChCs labeled in Cdh6-CreER;Dlx5/6-Flp;Ai65/+ mice were generated between E11 and E14 with peaks at E12 and E13 (Fig. $5 B, C$; E10: $0 \%, n=1$ mouse, 27 ChCs; E11: $16.3 \pm 3.5 \%$, $n=3$ mice, 60 ChCs; E12: $34.9 \pm 2.7 \%, n=4$ mice, $151 \mathrm{ChCs}$;
E13: $36.3 \pm 4.7 \%, n=3$ mice, 68 ChCs; E14: $16.2 \pm 3.7 \%, n=3$ mice, 61 ChCs; E15: 0\%, $n=2$ mice, 42 ChCs; E16: 0\%, $n=3$ mice, $81 \mathrm{ChCs})$. These birth dates are much earlier than time points (E15-E18) when the MGE produces predominantly ncChCs (Taniguchi et al., 2013). Together with our previous study, these results suggest that h-ChCs labeled in Cdh6-CreER;Dlx5/6Flp;Ai65/+ mice are produced earlier than the time window in which the MGE actively generates nc-ChCs.

\section{Local environment shapes terminal phenotypes of $\mathrm{h}$-ChCs and nc-ChCs}

Although our results showed that h-ChCs labeled in Cdh6CreER;Dlx5/6-Flp;Ai65/+ mice have temporal origins distinct from nc-ChCs produced from the late MGE, it remains unclear whether their terminal phenotypes such as axonal/synaptic organization and neurochemical marker expression are regulated intrinsically or extrinsically. To address this issue, we performed heterotopic transplantations using RFP-labeled young ChCs from the embryos of Nkx2.1-CreER;Ai14 donors. MGE tissues from E17 embryos, in which RFP expression was induced at E16, were used as a source of nc-ChCs (Fig. 6A). Young RFP ${ }^{+}$ hippocampal INs, presumably including h-ChCs, were taken from hippocampal tissues of E16 embryos, in which the MGE was labeled with RFP at E12 (Fig. 6B). Neocortical and hippocampal donor cells were transplanted into the hippocampus and the neocortex of P1 host pups, respectively, and analyzed for axonal expansion, the total number of AISs innervated by a single ChC, and CR expression at P24-P25 (host ages).

Strikingly, we found that donor ChCs display axonal expansion characteristic of endogenous ChCs in host cortical regions. nc-ChCs transplanted into the host hippocampus developed significantly larger $\mathrm{M}-\mathrm{L}$ axonal expansion than h-ChCs transplanted into the host neocortex (Fig. $6 C-F, H ; n=10$ cells for each; nc-ChCs transplanted into the host hippocampus: $469.0 \pm$ $16.8 \mu \mathrm{m}$; h-ChCs transplanted into the host neocortex: $249.9 \pm$ $8.1 \mu \mathrm{m}$; two-tailed Student's $t$ test, $p<0.0001)$. Their axonal expansion along the A-P axis was also significantly larger than that of h-ChCs transplanted into the host neocortex (Fig. 6G; $n=$ 10 cells for each; nc-ChCs transplanted into the host hippocampus: $578.1 \pm 16.7 \mu \mathrm{m}$; h-ChCs transplanted into the host neocortex: $357.9 \pm 17.2 \mu \mathrm{m}$; two-tailed Student's $t$ test, $p<0.0001$ ). The number of AISs innervated by a single nc-ChCs transplanted into the host hippocampus was significantly higher than those innervated by a single h-ChCs transplanted into the host neocortex (Fig. 6I, Table 7; nc-ChCs transplanted into the host hippocampus: $n=5$ cells, $659.1 \pm 54.1$ AISs; h-ChCs transplanted into the host hippocampus: $n=3$ cells, $286.7 \pm 55.2$ AISs; twotailed Student's $t$ test, $p=0.004$ ). These results suggest that extrinsic mechanisms inherent to the local cellular environment regulate $\mathrm{ChC}$ axonal/synaptic organization in a cortical-regionspecific manner.

To our surprise, we also found that donor ChCs express CR dependent on host cortical locations. Four of 26 nc-ChCs transplanted into the host hippocampus showed obvious CR expression, whereas none of $18 \mathrm{~h}$-ChCs transplanted into the host neocortex expressed CR (Fig. 7A-D). These results suggest that $\mathrm{CR}$ expression in h-ChCs is also regulated extrinsically.

\section{Discussion}

Although the hippocampus and the neocortex contain common canonical IN types, it remains largely unknown whether they have regional phenotypic variations. Furthermore, it is poorly understood whether local environment regulates terminal phe- 
A
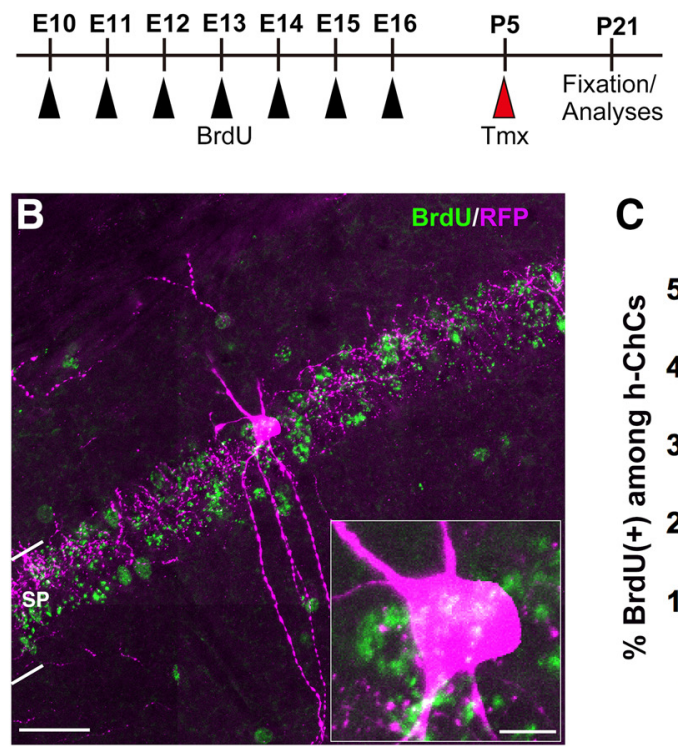

C

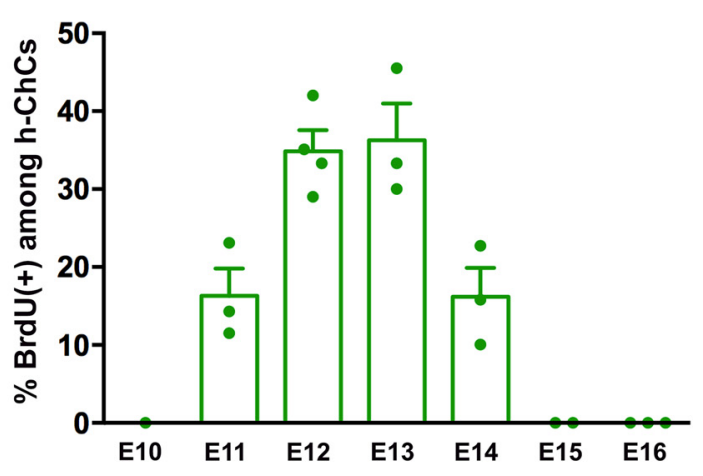

Figure 5. Temporal origins of h-ChCs labeled in Cdh6-CreER;Dlx5/6-Flp;Ai65 mice. A, Experimental timeline of BrdU-based birth dating. In Cdh6-CreER;D/x5/6-Flp;Ai65 mice, h-ChCs were labeled by tamoxifen injection at P5, paired with a single BrdU administration at the indicated date. Mice were analyzed at P21. B, Confocal projection image of an RFP ${ }^{+} h-C h C$ (magenta) labeled with BrdU (green) administrated at E12. A confocal single optical section in inset shows the enlarged view of RFP and BrdU signals in a soma. C, Quantification of the percentage of BrdU ${ }^{+}$cells among h-ChCs. h-ChCs are born between E11 and E14 with peaks at E12 and E13. (E10:0\%, $n=1$ mouse, 27 ChCs; E11: $16.3 \pm 3.5 \%, n=3$ mice, 60 ChCs; E12:34.9 $\pm 2.7 \%, n=4$ mice, 151 ChCs; E13:36.3 \pm $4.7 \%, n=3$ mice, $68 \mathrm{ChCs}$; E14: $16.2 \pm 3.7 \%, n=3$ mice, $61 \mathrm{ChCs}$; E15:0\%, $n=2$ mice, $42 \mathrm{ChCs}$; E16:0\%, $n=3$ mice, 81 ChCs). Data are presented as mean \pm SEM. Scale bars: $\boldsymbol{B}, 50 \mu$ m; inset in $B, 10 \mu \mathrm{m}$.

notypes of regional IN variants. In this study, we show that $C d h 6$ is expressed in all L2 ChCs examined in Nkx2.1-CreER;Ai14 mice and that $C d h 6-C r e E R$ mice provide a reliable genetic strategy to target h-ChCs. Using Cdh6-CreER mice, we find that h-ChCs develop axonal arbors that cover a wider area and innervate more PNs than nc-ChCs and include a novel CR-expressing subpopulation that has never been found in nc-ChCs. We also show that h-ChCs labeled in Cdh6-CreER;Dlx5/6-Flp;Ai65/+ mice are generated earlier than the time window in which the MGE predominantly produce nc-ChCs. Furthermore, we discover that region-specific local environment shapes both axonal/synaptic organization and CR expression. These findings provide novel insight into the specification and differentiation of regional IN variants in the cortex.

Here, using PCR-based amplification of cDNAs from a small number of young nc-ChCs, we screened 16 classic cadherins and identified Cdh4, Cdh6, and Cdh9. We further tested specificity of expression of these cadherins by carrying out ISH in representative cortical IN types including PV-INs, SOM-INs, and VIPINs in addition to nc-ChCs. Interestingly, we found that all L2 nc-ChCs tested in Nkx2.1-CreER;Ai14 mice expressed Cdh6; in contrast, a small fraction of other IN types expressed Cdh6. Unlike an RNA sequencing or a quantitative PCR method, our screening strategy lacks quantitative information and might not be able to detect low levels of gene expression. Nevertheless, our results provide the first evidence that a relatively homogenous canonical IN type expresses specific types of cadherins.

In this study, there are a few points of concern that we should take into account. First, our genetic strategy using Cdh6-CreER mice likely captures a fraction of $C d h \sigma^{+}$INs because CreER has weaker activity than straight Cre. Second, although our genetic approach could label at least some h-ChCs in representative subregions of the hippocampus and identify $\mathrm{CR}^{+} \mathrm{h}$-ChCs that have never been reported in previous studies, we cannot exclude the possibility that there exist $C d h 6^{-}$h-ChCs that may have different morphological and physiological properties and developmental origins from $C d h 6^{+}$h-ChCs. One should take this possibility into account, especially in the CA3 and the DG, because our genetic strategy labels predominantly h-ChCs in the CA1. Third, although our previous studies demonstrated that the late MGE (E15-E18) produces numerous nc-ChCs, there remains a possibility that the early MGE contributes to a minor fraction of ncChCs. The fact that in utero electroporation targeting E12 MGE can label a few nc-ChCs (Tai et al., 2014) may support this idea. Therefore, the interpretations of our results from the present study should not be oversimplified. Nevertheless, identification of two distinct ChC subpopulations that are separately localized in the hippocampus and the neocortex and display differences in temporal origins, axonal/synaptic organization, and marker expression (i.e., h-ChCs labeled in Cdh6-CreER;Dlx5/6-Flp;Ai65/+ mice and nc-ChCs produced from the late MGE) provides an important insight into the specification and development of regional variants of ChCs.

Previous studies from the laboratory of Christopher McBain showed that canonical IN types have regional variations of physiological and neurochemical properties in the hippocampus and the neocortex (Tricoire et al., 2010; Chittajallu et al., 2013). Our current results support and expand this view. First, we find that h-ChCs labeled in Cdh6-CreER;Dlx5/6-Flp;FSF-LSL-RFP mice innervate a wider territory and more PNs than typical nc-ChCs, suggesting a regional difference in the size of cooperating circuit modules. Second, we find that h-ChCs but not nc-ChCs contain a novel CR-expressing subset, suggesting a functional subdivision of h-ChCs. These differences may be important for generating region-specific spatiotemporal patterns of PN activity. 

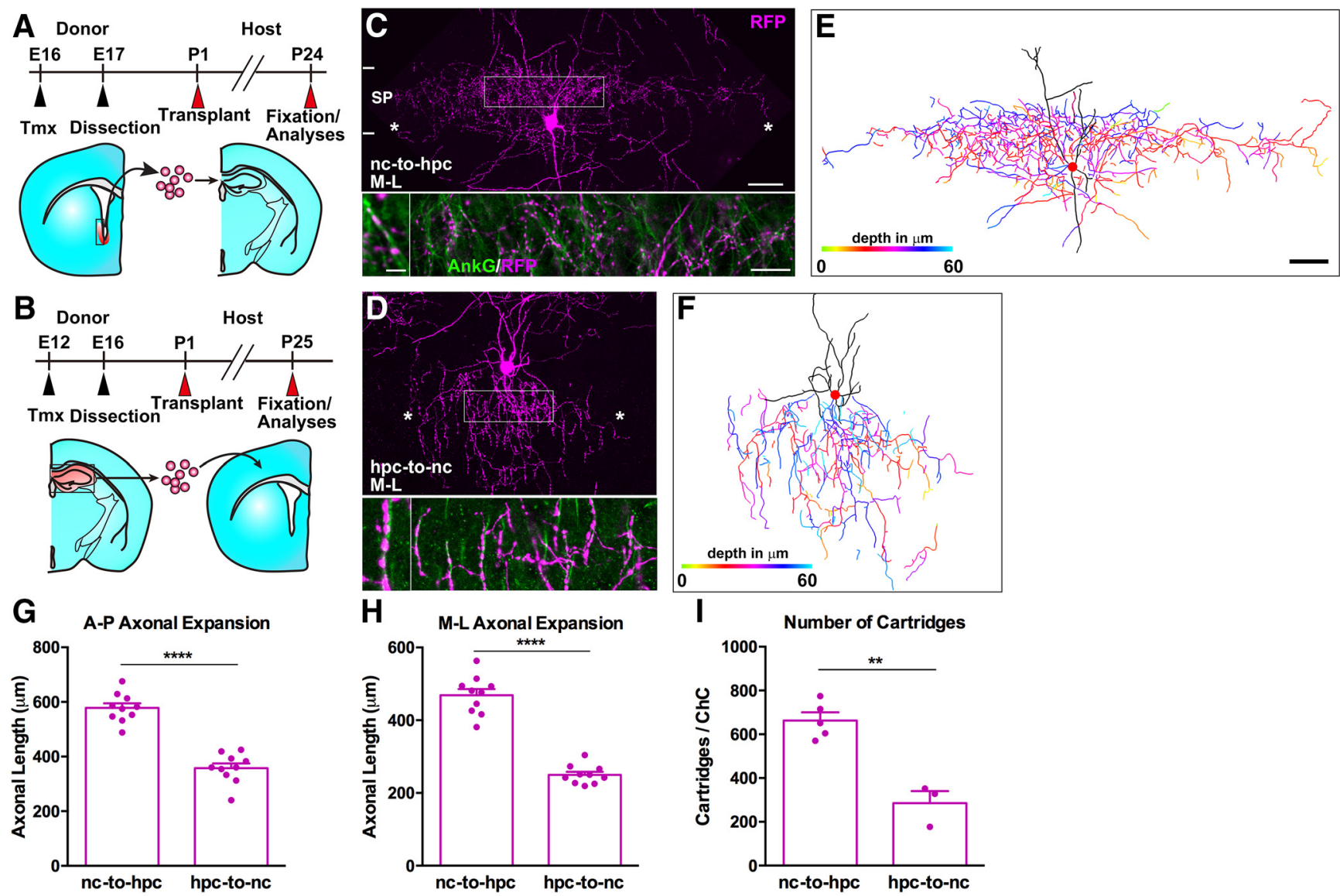

Figure 6. Size of axonal arbors of transplanted ChCs is dependent on host cortical environment. $A, B$, Schematics showing experimental strategies for the heterotopic transplantation of $\mathrm{nc}$-ChCs (A) and h-ChCs (B). E17 MGE cells from Nkx2.1-CreER;Ai14 embryos induced at E16 were transplanted into the hippocampus of P1 host animals (A). E16 hippocampal cells from Nkx2.1-CreER;Ai14 embryos induced at E12 were transplanted into the neocortex of P1 host animals $(\boldsymbol{B})$. $\boldsymbol{C}, \boldsymbol{D}$, Top, Confocal projection images representing the M-L extent of ChC axonal arbors in coronal sections. An $\mathrm{h}$-ChC transplanted into the host neocortex and an nc-ChC transplanted into the host hippocampus are shown in $\mathbf{C}$ and $\boldsymbol{D}$, respectively. Asterisks indicate both ends of axonal arbors. Confocal single optical sections in lower right panels represent enlarged images of boxed areas in top showing axonal varicosities (magenta) apposed to AISs (green) stained with anti-AnkG antibodies. Bottom left panels show individual cartridge structures. $\boldsymbol{E}, \boldsymbol{F}, 3 \mathrm{D}$ reconstructions of an $\mathrm{h}$-ChC transplanted into the host neocortex $(\boldsymbol{E})$ and an nc-ChC transplanted into the host hippocampus $(\boldsymbol{F})$ in coronal sections. Axonal processes are color coded according to their depth. $\mathbf{G}, \boldsymbol{H}$, Quantification of the $\mathrm{A}-\mathrm{P}(\boldsymbol{G})$ and $\mathrm{M}-\mathrm{L}(\boldsymbol{H})$ extent of axonal arbors in nc-ChCs transplanted into the host hippocampus and $\mathrm{h}$-ChCs transplanted into the host neocortex (A-P extent: $n=10$ cells for each; $\mathrm{nc}-\mathrm{ChCs}$ transplanted into the host hippocampus: $578.1 \pm 16.7 \mu \mathrm{m}$; $\mathrm{h}$-ChCs transplanted into the host neocortex: $357.9 \pm 17.2 \mu \mathrm{m} ; \mathrm{M}$-L extent: $n=10$ cells for each; $\mathrm{nc}$-ChCs transplanted into the host hippocampus: $469.0 \pm 16.8 \mu \mathrm{m} ; \mathrm{h}$-ChCs transplanted into the host neocortex: $249.9 \pm 8.1 \mu \mathrm{m} ;$ two-tailed Student's t test, $p<0.0001$ ).I, Quantification of the number of AlSs innervated by a single transplanted ChC (nc-ChCs transplanted into the hosthippocampus: $n=5$ cells, $659.1 \pm 54.1$ AlSs; $h$-ChCs transplanted into the host hippocampus: $n=3$ cells, $286.7 \pm 55.2$ AlSs; two-tailed Student's t test, $p=0.004$ ). Data are presented as mean \pm SEM. Scale bars, $50 \mu \mathrm{m}$ (top in $\boldsymbol{C}, \boldsymbol{D}$ and $\boldsymbol{E}, \boldsymbol{F}$ ), $20 \mu \mathrm{m}$ (bottom right panels in $\boldsymbol{C}, \boldsymbol{D}), 5 \mu \mathrm{m}$ (bottom left panels in $\boldsymbol{C}, \boldsymbol{D}$ ).

Table 7. Measured values used to estimate the average number of AISs innervated by a single transplanted ChC

\begin{tabular}{llll}
\hline & $\begin{array}{l}\text { Total no. of } \\
\text { boutons }\end{array}$ & $\begin{array}{l}\text { Boutons per AIS } \\
(n=5 \text { AlSs each })\end{array}$ & No. of AISs \\
\hline $\begin{array}{l}\text { hpc-to-nc } \\
\text { Average }\end{array}$ & & & \\
Cell 1 & 671 & $3.8 \pm 0.4$ & $286.7 \pm 55.2$ \\
Cell 2 & 1189 & $3.4 \pm 0.5$ & 176.6 \\
Cell 3 & 1335 & $4.0 \pm 0.4$ & 349.7 \\
nc-to-hpc & & & 333.8 \\
Average & & $3.0 \pm 0.4$ & \\
Cell 1 & 1520 & $2.8 \pm 0.4$ & $659.1 \pm 54.1$ \\
Cell 2 & 2190 & $3.4 \pm 0.2$ & 782.7 \\
Cell 3 & 1914 & $2.8 \pm 0.4$ & 562.9 \\
Cell 4 & 2132 & $2.8 \pm 0.5$ & 761.4 \\
Cell 5 & 1910 & & 682.1 \\
\hline
\end{tabular}

It has been suggested that embryonic origins play a role in laminar positioning and fate determination of neocortical INs (Wonders and Anderson, 2006; Gelman and Marín, 2010; Taniguchi, 2014). However, it has been largely unknown whether hippocampal and neocortical variants of canonical IN types could have distinct embryonic origins. More recently, it has been shown that IN variants in the hippocampus and the neocortex have distinct spatial origins. For example, O-LM cells arise from both the MGE and the CGE, whereas Martinotti cells solely derive from the MGE (Chittajallu et al., 2013). h-NGCs are largely produced in the MGE, whereas nc-NGCs arise predominantly from the CGE (Tricoire et al., 2010). Currently, there is no evidence supporting differential spatial origins of h-ChCs and nc-ChCs. All previous studies suggest that ChCs are generated exclusively in the MGE, but not the CGE (Miyoshi et al., 2010; Tricoire et al., 2011; Inan et al., 2013; Taniguchi et al., 2013). However, our novel finding of $\mathrm{CR}^{+} \mathrm{h}$-ChCs raises an intriguing question about their spatial origin. Because the majority of $\mathrm{CR}^{+}$INs are derived from the CGE (Miyoshi et al., 2010; Tricoire et al., 2011), CR ${ }^{+}$ 


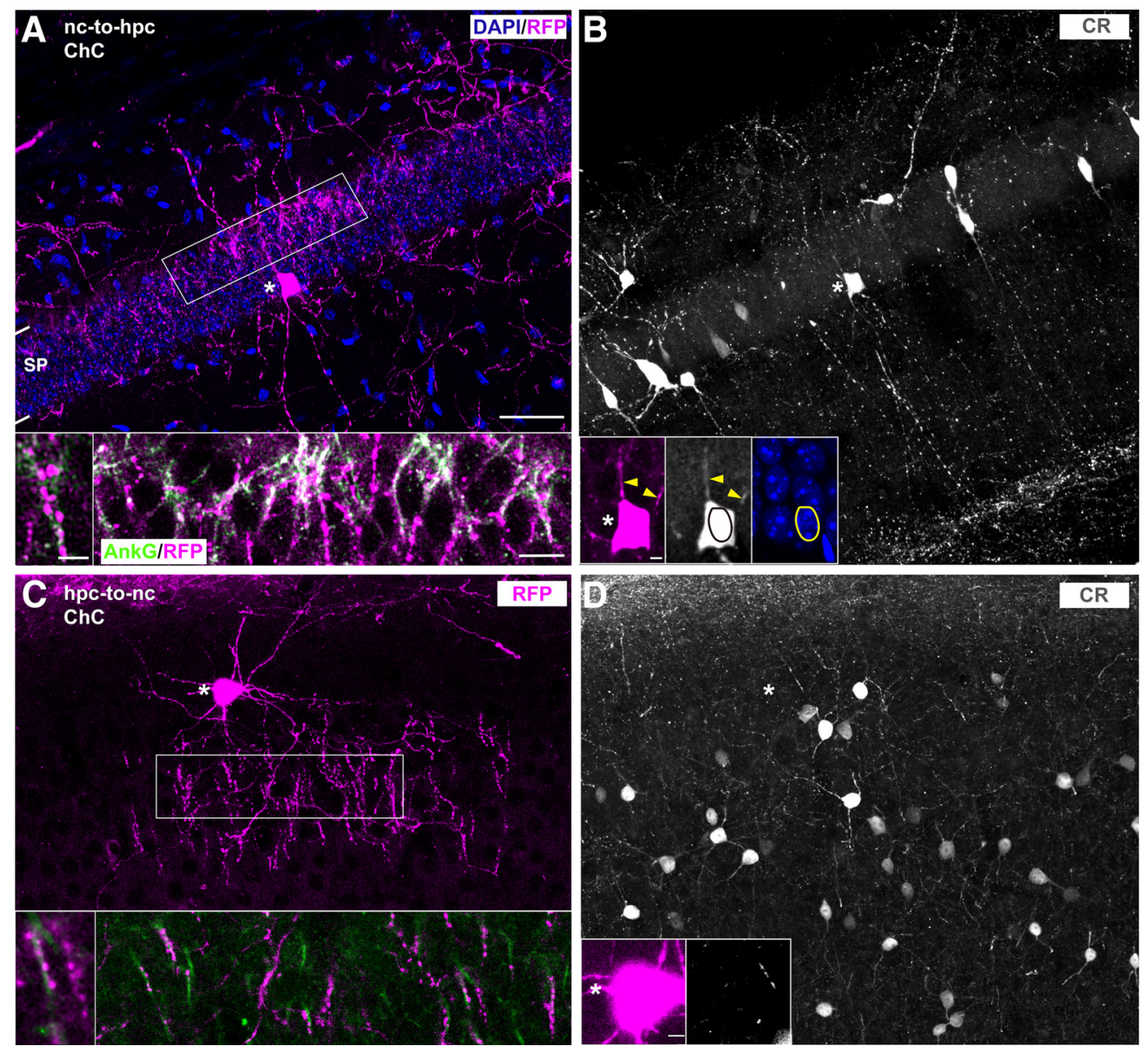

Figure 7. CR expression in transplanted ChCs is dependent on host cortical environment. $\boldsymbol{A}, \boldsymbol{B}$, Confocal projection images of DAPI/RFP signals ( $\boldsymbol{A}$, top) and CR signals ( $\boldsymbol{B})$ in an nc-ChC transplanted into the host hippocampus. A confocal single optical section in the bottom right panel in $\boldsymbol{A}$ represents enlarged image of the boxed area in the top showing axonal varicosities (magenta) apposed to AISs (green) stained with anti-AnkG antibodies. Bottom left panel in $\boldsymbol{A}$ shows individual cartridge structures. Confocal single optical sections in insets in $\boldsymbol{B}$ represent magnified images of the cell marked with asterisk showing RFP, CR, and DAPI signals from left to right. Arrowheads indicate CR signals in processes. Black and yellow circles show the position of the nucleus in the RFP ${ }^{+} \mathrm{ChC}$ deduced from DAPI staining. $\boldsymbol{C}, \boldsymbol{D}$, Confocal projection images of RFP signals ( $\boldsymbol{C}$, top) and CR signals (D) in an h-ChC transplanted into the host neocortex. A confocal single optical section in the bottom right panel in Crepresents enlarged image of the boxed area in the top showing axonal varicosities (magenta) apposed to AISs (green) stained with anti-AnkG antibodies. Bottom left panel in C shows individual cartridge structures. Confocal single optical sections in insets in $\boldsymbol{D}$ represent magnified images of the cell marked with asterisk showing RFP (left) and CR (right) signals. Note that there is no colocalization between RFP and CR signals in the h-ChC transplanted into the host neocortex. Scale bars, $50 \mu \mathrm{m}(\boldsymbol{B}, \boldsymbol{D}$; top in $A, C), 20 \mu \mathrm{m}$ (bottom right panels in $A, C), 5 \mu \mathrm{m}$ (bottom left panels in $\boldsymbol{A}, \boldsymbol{C}$, and $5 \mu \mathrm{m}$ (insets in $\boldsymbol{B}, \boldsymbol{D}$ ).

h-ChCs could originate from the CGE. Tricoire and colleagues performed morphological, physiological, and electrophysiological characterizations of CGE derived h-INs using GAD65-GFP transgenic mice, which they reported in half of CGE-derived INs, but found no $\mathrm{CR}^{+}$h-ChCs (López-Bendito et al., 2004; Tricoire et al., 2011). It has been reported that $5-\mathrm{HT}_{3 \mathrm{~A}} \mathrm{R}-\mathrm{GFP}$ transgenic mice label nearly all CGE-derived INs (Lee et al., 2010; Vucurovic et al., 2010; Chittajallu et al., 2013). Therefore, it would be interesting to test whether $\mathrm{CR}^{+} \mathrm{h}$-ChCs is labeled with GFP in Cdh6CreER;Dlx5/6-Flp;Ai65;5-HT ${ }_{3 A} R$-GFP mice.

In this study, we add the novel view that regional variants of canonical IN types could have distinct temporal origins. We provide evidence that h-ChCs labeled in Cdh6-CreER;Dlx5/6-Flp; FSF-LSL-RFP mice are generated in an early time window with a peak between $\mathrm{E} 12$ and $\mathrm{E} 13$, in contrast to $\mathrm{nc}-\mathrm{ChCs}$, which are produced from the late MGE with a peak between E16 and E17 (Taniguchi et al., 2013). This is consistent with our observation that the expression of reporters in the late MGE progenitors in Nkx2.1-CreER knock-in mice fails to label h-ChCs.

Previous studies have shown the correlation between embryonic origins and terminal phenotypes of hippocampal and neocortical IN variants. For example, O-LM cells expressing serotonin receptors $\left(5-\mathrm{HT}_{3 \mathrm{~A}} \mathrm{Rs}\right)$ are derived from the CGE, whereas Martinotti cells expressing no 5- $\mathrm{HT}_{3 \mathrm{~A}} \mathrm{Rs}$ originate from the MGE (Chittajallu et al., 2013). h-NGCs expressing nNOS are derived from the MGE, whereas nc-NGCs displaying weak nNOS expression arise from the CGE (Tricoire et al., 2010). Furthermore, a recent study has shown that distinct temporal origins of hippocampal basket cells are correlated with two different populations that differ in their expression levels of PV, laminar positions of projection targets, and the ratio of excitatory to inhibitory inputs (Donato et al., 2015). Although these findings suggest that terminal phenotypes are regulated intrinsically through cell type specification in distinct spatiotemporal origins, recent evidence has also proposed that IN properties can be modulated by extrinsic factors present in local environments when they are integrated into neural networks. For instance, neuronal activity and experience modulate electrophysiological features of neocortical PV-expressing BCs by adjusting the expression level of Kv2.1 through the expression of ER81, a transcription factor of the ETS family (Dehorter et al., 2015). Therefore, it has remained elusive whether intrinsic or extrinsic mechanisms regulate region- 
specific terminal phenotypes. Here, we provide direct evidence that extrinsic mechanisms shape terminal phenotypes of h-ChCs labeled in Cdh6-CreER;Dlx5/6-Flp;FSF-LSL-RFP mice and ncChCs generated from the late MGE. Using heterotopic transplantation techniques, we reveal that cellular environments, rather than intrinsic specification of ChCs, control their axonal/synaptic organization and CR expression in the hippocampus and the neocortex. Neuronal activity or molecular cues controlling axonal extension, branching, and synapse formation could be plausible candidates for extrinsic regulators. Although the region-specific terminal phenotypes we analyzed in this study are not intrinsically regulated, this does not rule out the possibility that embryonic specification in distinct time windows differentiate intrinsic features of the h-ChCs and the nc-ChCs. Potential intrinsic differences between the $\mathrm{h}$-ChCs and the nc-ChCs may include guidance receptors that determine whether they migrate to the hippocampus or the neocortex. Another possibility is that the h-ChCs and the nc-ChCs might express different sets of channels that underlie intrinsic electrophysiological properties.

In summary, we demonstrate that h-ChCs and nc-ChCs could have discrete terminal phenotypes, including expression of the neurochemical marker and axonal/synaptic organization. Although h-ChCs and nc-ChCs appear to display distinct temporal origins, these terminal phenotypes are shaped by region-specific cellular environment. These results complement previous studies showing that cardinal IN types in the hippocampus and the neocortex have distinct spatial origins and terminal phenotypes. Investigating terminal phenotypes of hippocampal and neocortical IN variants systematically and addressing whether they are regulated by nature or nurture will facilitate our understanding of how canonical IN types acquire further modifications suitable for distinct cortical regions.

\section{References}

Batista-Brito R, Fishell G (2009) The developmental integration of cortical interneurons into a functional network. Curr Top Dev Biol 87:81-118. CrossRef Medline

Chittajallu R, Craig MT, McFarland A, Yuan X, Gerfen S, Tricoire L, Erkkila B, Barron SC, López CM, Liang BJ, Jeffries BW, Pelkey KA, McBain CJ (2013) Dual origins of functionally distinct O-LM interneurons revealed by differential 5-HT(3A)R expression. Nat Neurosci 16:1598-1607. CrossRef Medline

Dehorter N, Ciceri G, Bartolini G, Lim L, del Pino I, Marín O (2015) Tuning of fast-spiking interneuron properties by an activity-dependent transcriptional switch. Science 349:1216-1220. CrossRef Medline

Donato F, Chowdhury A, Lahr M, Caroni P (2015) Early- and late-born parvalbumin basket cell subpopulations exhibiting distinct regulation and roles in learning. Neuron 85:770-786. CrossRef Medline

Gelman DM, Marín O (2010) Generation of interneuron diversity in the mouse cerebral cortex. Eur J Neurosci 31:2136-2141. CrossRef Medline

Harris KD, Shepherd GM (2015) The neocortical circuit: themes and variations. Nat Neurosci 18:170-181. CrossRef Medline

Hippenmeyer S, Vrieseling E, Sigrist M, Portmann T, Laengle C, Ladle DR, Arber S (2005) A developmental switch in the response of DRG neurons to ETS transcription factor signaling. PLoS Biol 3:e159. CrossRef Medline

Huang ZJ (2014) Toward a genetic dissection of cortical circuits in the mouse. Neuron 83:1284-1302. CrossRef Medline

Inan M, Blázquez-Llorca L, Merchán-Pérez A, Anderson SA, DeFelipe J, Yuste R (2013) Dense and overlapping innervation of pyramidal neurons by chandelier cells. J Neurosci 33:1907-1914. CrossRef Medline

Inoue T, Tanaka T, Suzuki SC, Takeichi M (1998) Cadherin-6 in the developing mouse brain: expression along restricted connection systems and synaptic localization suggest a potential role in neuronal circuitry. Dev Dyn 211:338-351. Medline
Jiang X, Shen S, Cadwell CR, Berens P, Sinz F, Ecker AS, Patel S, Tolias AS (2015) Principles of connectivity among morphologically defined cell types in adult neocortex. Science 350:aac9462. CrossRef Medline

Jones EG (1975) Varieties and distribution of non-pyramidal cells in the somatic sensory cortex of the squirrel monkey. J Comp Neurol 160:205267. CrossRef Medline

Kay JN, De la Huerta I, Kim IJ, Zhang Y, Yamagata M, Chu MW, Meister M, Sanes JR (2011) Retinal ganglion cells with distinct directional preferences differ in molecular identity, structure, and central projections. J Neurosci 31:7753-7762. CrossRef Medline

Kepecs A, Fishell G (2014) Interneuron cell types are fit to function. Nature 505:318-326. CrossRef Medline

Klausberger T, Somogyi P (2008) Neuronal diversity and temporal dynamics: the unity of hippocampal circuit operations. Science 321:53-57. CrossRef Medline

Lee S, Hjerling-Leffler J, Zagha E, Fishell G, Rudy B (2010) The largest group of superficial neocortical GABAergic interneurons expresses ionotropic serotonin receptors. J Neurosci 30:16796-16808. CrossRef Medline

López-Bendito G, Sturgess K, Erdelyi F, Szabó G, Molnár Z, Paulsen O (2004) Preferential origin and layer destination of GAD65-GFP cortical interneurons. Cereb Cortex 14:1122-1133. CrossRef Medline

Madisen L et al. (2015) Transgenic mice for intersectional targeting of neural sensors and effectors with high specificity and performance. Neuron 85:942-958. CrossRef Medline

Madisen L, Zwingman TA, Sunkin SM, Oh SW, Zariwala HA, Gu H, Ng LL, Palmiter RD, Hawrylycz MJ, Jones AR, Lein ES, Zeng H (2010) A robust and high-throughput Cre reporting and characterization system for the whole mouse brain. Nat Neurosci 13:133-140. CrossRef Medline

Miyoshi G, Butt SJ, Takebayashi H, Fishell G (2007) Physiologically distinct temporal cohorts of cortical interneurons arise from telencephalic Olig2-expressing precursors. J Neurosci 27:7786-7798. CrossRef Medline

Miyoshi G, Hjerling-Leffler J, Karayannis T, Sousa VH, Butt SJ, Battiste J, Johnson JE, Machold RP, Fishell G (2010) Genetic fate mapping reveals that the caudal ganglionic eminence produces a large and diverse population of superficial cortical interneurons. J Neurosci 30:1582-1594. CrossRef Medline

Osterhout JA, Josten N, Yamada J, Pan F, Wu SW, Nguyen PL, Panagiotakos G, Inoue YU, Egusa SF, Volgyi B, Inoue T, Bloomfield SA, Barres BA, Berson DM, Feldheim DA, Huberman AD (2011) Cadherin-6 mediates axon-target matching in a non-image-forming visual circuit. Neuron 71 : 632-639. CrossRef Medline

Somogyi P (1977) A specific 'axo-axonal' interneuron in the visual cortex of the rat. Brain Res 136:345-350. CrossRef Medline

Suzuki SC, Inoue T, Kimura Y, Tanaka T, Takeichi M (1997) Neuronal circuits are subdivided by differential expression of type-II classic cadherins in postnatal mouse brains. Mol Cell Neurosci 9:433-447. CrossRef Medline

Szentágothai J (1975) The 'module-concept' in cerebral cortex architecture. Brain Res 95:475-496. CrossRef Medline

Tai Y, Janas JA, Wang CL, Van Aelst L (2014) Regulation of chandelier cell cartridge and bouton development via DOCK7-mediated ErbB4 activation. Cell Rep 6:254-263. CrossRef Medline

Takács VT, Szőnyi A, Freund TF, Nyiri G, Gulyás AI (2015) Quantitative ultrastructural analysis of basket and axo-axonic cell terminals in the mouse hippocampus. Brain Struct Funct 220:919-940. CrossRef Medline

Takeichi M (2007) The cadherin superfamily in neuronal connections and interactions. Nat Rev Neurosci 8:11-20. CrossRef Medline

Taniguchi H (2014) Genetic dissection of GABAergic neural circuits in mouse neocortex. Front Cell Neurosci 8:8. CrossRef Medline

Taniguchi H, He M, Wu P, Kim S, Paik R, Sugino K, Kvitsani D, Fu Y, Lu J, Lin Y, Miyoshi G, Shima Y, Fishell G, Nelson SB, Huang ZJ (2011) A resource of Cre driver lines for genetic targeting of GABAergic neurons in cerebral cortex. Neuron 71:995-1013. CrossRef Medline

Taniguchi H, Lu J, Huang ZJ (2013) The spatial and temporal origin of chandelier cells in mouse neocortex. Science 339:70-74. CrossRef Medline

Tricoire L, Pelkey KA, Daw MI, Sousa VH, Miyoshi G, Jeffries B, Cauli B, Fishell G, McBain CJ (2010) Common origins of hippocampal Ivy and 
nitric oxide synthase expressing neurogliaform cells. J Neurosci 30:21652176. CrossRef Medline

Tricoire L, Pelkey KA, Erkkila BE, Jeffries BW, Yuan X, McBain CJ (2011) A blueprint for the spatiotemporal origins of mouse hippocampal interneuron diversity. J Neurosci 31:10948-10970. CrossRef Medline

Viney TJ, Lasztoczi B, Katona L, Crump MG, Tukker JJ, Klausberger T, Somogyi P (2013) Network state-dependent inhibition of identified hippocampal CA3 axo-axonic cells in vivo. Nat Neurosci 16:1802-1811. CrossRef Medline

Vucurovic K, Gallopin T, Ferezou I, Rancillac A, Chameau P, van Hooft JA, Geoffroy H, Monyer H, Rossier J, Vitalis T (2010) Serotonin 3A receptor subtype as an early and protracted marker of cortical interneuron subpopulations. Cereb Cortex 20:2333-2347. CrossRef Medline
Watakabe A, Komatsu Y, Ohsawa S, Yamamori T (2010) Fluorescent in situ hybridization technique for cell type identification and characterization in the central nervous system. Methods 52:367-374. CrossRef Medline

Wonders CP, Anderson SA (2006) The origin and specification of cortical interneurons. Nat Rev Neurosci 7:687-696. CrossRef Medline

Xu HT, Han Z, Gao P, He S, Li Z, Shi W, Kodish O, Shao W, Brown KN, Huang K, Shi SH (2014) Distinct lineage-dependent structural and functional organization of the hippocampus. Cell 157:1552-1564. CrossRef Medline

Yu YC, Bultje RS, Wang X, Shi SH (2009) Specific synapses develop preferentially among sister excitatory neurons in the neocortex. Nature 458: 501-504. CrossRef Medline 